\title{
The impact of corporate social performance on financial risk and utility: a longitudinal analysis
}

Article

Accepted Version

Oikonomou, I., Brooks, C. and Pavelin, S. (2012) The impact of corporate social performance on financial risk and utility: a longitudinal analysis. Financial Management, 41 (2). pp. 483515. ISSN 1755-053X doi: https://doi.org/10.1111/j.1755053X.2012.01190.x Available at https://centaur.reading.ac.uk/26242/

It is advisable to refer to the publisher's version if you intend to cite from the work. See Guidance on citing.

To link to this article DOI: http://dx.doi.org/10.1111/j.1755-053X.2012.01190.x

Publisher: Wiley

All outputs in CentAUR are protected by Intellectual Property Rights law, including copyright law. Copyright and IPR is retained by the creators or other copyright holders. Terms and conditions for use of this material are defined in the End User Agreement.

www.reading.ac.uk/centaur 
Central Archive at the University of Reading

Reading's research outputs online 
This is the authors' accepted manuscript of an article published in Financial Management. The definitive version is available at www3.interscience.wiley.com 


\title{
The Impact of Corporate Social Performance on Financial Risk and Utility: A Longitudinal Analysis
}

\begin{abstract}
This study focuses on the wealth-protective effects of socially responsible firm behavior by examining the association between corporate social performance (CSP) and financial risk for an extensive panel data sample of S\&P 500 companies between the years 1992 and 2009. In addition, the link between CSP and investor utility is investigated. The main findings are that corporate social responsibility is negatively but weakly related to systematic firm risk and that corporate social irresponsibility is positively and strongly related to financial risk. The fact that both conventional and downside risk measures lead to the same conclusions adds convergent validity to the analysis. However, the risk-return trade-off appears to be such that no clear utility gain or loss can be realized by investing in firms characterized by different levels of social and environmental performance. Overall volatility conditions of the financial markets are shown to play a moderating role in the nature and strength of the CSP-risk relationship.
\end{abstract}

Ioannis Oikonomou is a Lecturer in Finance at the ICMA Centre at the University of Reading in Whiteknights Reading, UK.

Chris Brooks is a Professor of Finance at the ICMA Centre at the University of Reading in Whiteknights Reading, UK.

Stephen Pavelin is a Professor in Business and Society at the School of Management at the University of Bath in Bath, UK.

The authors thank an anonymous referee for useful comments that substantially improved this article. The usual disclaimer applies. 
Within the rapidly evolving research area of Corporate Social Responsibility (CSR), a significant portion of the relevant theoretical and empirical literature has concentrated on studying the specificities of the relationship between the corporate social performance (CSP) and measures of the corporate financial performance (CFP) of the firm. For many researchers, managers, and investors, the question of whether there is a business case for CSR is of key importance. Perceptions of a positive (or negative) direct or indirect relationship between a corporation's social responsibility and its bottom line promote (or deter) the implementation of CSR principles in both corporate and investment strategies. The academic debate concerning the nature of the link between CSP and CFP is a persistent and controversial one. Due to a variety of definitional, measurement, and methodological issues, there is no consensus in the relevant literature, either at the firm or portfolio level of analysis, with results often in sharp conflict (Griffin and Mahon, 1997; Margolis and Walsh, 2003) some studies indicate a positive CSP-CFP relationship (Hillman and Keim, 2001), others point to a negative link (Brammer, Brooks, and Pavelin, 2006) or to no significant association between the two (Renneboog, Ter Horst, and Zhang, 2008a; Bauer, Koedijk, and Otten, 2005). Among these studies, the common denominator is the use of measures of financial performance that focus on firm profitability (accounting measures) or on stock returns (market measures), sometimes using risk (either accounting or market risk, respectively) only as an adjustment factor.

The inherent assumption in these papers is that CSP can influence CFP solely through a front door mechanism. Under the stakeholder management perspective, CSP is expected to contribute to the creation of sustainable comparative advantages that will enhance firm profitability and lead to an overall positive CSP-CFP relationship (Jones, 1995). In contradiction to this, there are those who view CSR practices as a misappropriation and misallocation of valuable corporate resources which are detrimental to firm performance 
(Friedman, 1970). The final possibility is that there are so many intervening variables between CSP and CFP that identifying a consistent, statically significant relationship between the two is prohibitively difficult (Ullmann, 1985).

In this study, we attempt to offer an alternative empirical pathway in relation to the CSP-CFP connection by investigating the possibility of the existence of a back door mechanism between the two so that CSP has wealth-protective instead of wealth-enhancing effects that are captured in the corporations' stock market valuations. To investigate such effects, we will focus our analysis upon the relationship between CSP and financial risk (rather than profitability or returns on share ownership) at the firm level. Thus, in a substantive departure from previous studies of the CSP-CFP link, risk will be employed as a key dependent variable.

The relationship between CSP and financial risk carries considerable potential importance for managers and investors alike. Managers seeking to reduce the uncertainty to which their businesses fortunes are subject would find it useful to know whether improved CSP is likely to increase or decrease the variability of future firm performance. This is especially true if one accepts that the claim of Cox, Brammer, and Millington, (2004, p.29) that "there is a broad consensus in the conceptual literature that many financial gains from improved social performance accrue in the long run" also applies to the effects of CSP on financial risk. It may be the case that companies which have invested in environmental programs that utilize renewable energy and clean fuels or other firms that make great efforts to ensure the optimal quality and safety characteristics of their products and services might be better equipped to cope with adverse systematic economic shocks than their competitors who are not involved in such practices. Secondly, because of the alleged long-term, risk reductive effects of socially responsible corporate activity, the stocks of firms with high levels of CSP might be attractive to specific types of institutional investors such as pension funds that "tend 
to have significantly predictable, long-term outflows to beneficiaries” (Ryan and Schneider, 2002, p.560). This reasoning is empirically supported by Cox et al. (2004) who find a positive and significant relationship between the proportion of company ownership by pension funds/life assurance companies and CSP.

Lastly, given the turmoil in financial markets during the 2000-2002 (caused by the bursting of the dot-com bubble) and 2008-2009 periods (real estate downturn and systemic crisis), with most stock indices around the globe losing a significant part of their values within a few months, the issue becomes even more pivotal. ${ }^{1}$ In times such as these, the stylized fact is that the average investor's risk aversion increases and more attention is directed towards the avoidance of high risk rather than the reaping of great returns. The hypothesized wealth-protective effects of CSP would make the respective firm stocks highly desirable investment assets.

The remainder of this study is structured as follows. Section I discusses the existing evidence in the relation between CSP and financial risk per se. Section II provides the theoretical framework upon which this empirical work is based. The characteristics of the data that are utilized and the construction of the CSP and financial risk/utility measures employed are introduced in Section III. Section IV contains the details of the methodological process that is implemented. Section V presents the results of the various analyses that have been performed whereas Section VI draws conclusions and makes suggestions for future research.

\footnotetext{
${ }^{1}$ Some academics have compared the latter situation with the stock market crash during the Great Depression (Eichengreen and O’ Rourke, 2009).
} 


\section{CSP and Financial Risk: The Existing Evidence}

Empirical testing of the hypothesis of the wealth-protective consequences of corporate social and environmental behavior through an examination of the link between CSP and financial risk is a route that a relatively small number of researchers have taken. ${ }^{2}$ Given the existence of a significant number of conceptual links between CSP and financial risk, this observation is especially startling. Spicer (1978) was amongst the first to conduct such a study. He uses the Controls for Environmental Pollution (CEP) reports as a CSP measure and finds negative Spearman rank order correlations between it and measures of total and systematic risk, thus providing some early empirical support for a risk-reducing effect of strong CSP. Aupperle, Carroll, and Hatfield, (1985) report a correlation analysis in which CSP constructs created from the results of a forced-choice survey of corporate Chief Executive Officers (CEOs) are used along with accounting measures of CFP (return on assets (ROA)) and risk (beta, Value Line's safety index). No measure of financial performance is significantly related to factors like the employment of social forecasting or having a social responsibility committee, but all of the latter are significantly and negatively related to total financial risk and insignificantly negatively associated with long-term beta. Building on this paper, Aupperle and Pham (1989) aggregate the non-economic components of CSP and use a variety of accounting (ROA, return on equity (ROE), and return on stock (ROS)) and market (stock price growth, total return to investor) measures of CFP. They find no significant relationship between CSP and any measure of financial performance or even financial risk.

\footnotetext{
${ }^{2}$ From this point onwards, unless otherwise mentioned, the term "financial risk" will be used to mean "market risk".
} 
Somewhat similarly, McGuire, Sungren, and Schneeweis, (1988) use a sample of large US firms rated in Fortune's 'America's Most Admired Companies' reputation index (one attribute of which is environmental and social responsibility). They use multiple CFP measures (total return, asset growth, alpha, and others) and risk measures (operating leverage and beta) and run regressions for different time windows. They find that CSP is positively (and strongly) related to CFP and negatively (and less strongly) related to both prior and subsequent systematic risk.

Orlitzky and Benjamin's (2001) meta-analysis summarizes the characteristics of the datasets, methodologies and conclusions of the previously presented research papers along with those of many other studies that were published between 1976 and 1997. Their summary of previous research is indicative of the limitations of the empirical work in this area. For example, they demonstrate (Table I, pp. 380-382) that the entire set of the meta-analyzed studies, consists of very narrow data samples, which contain between less than a dozen (Baldwin, Tower, Litvak, Karpen, Jackson, and McTigue, 1986) to a maximum of 469 observations (Waddock and Graves, 1997). Furthermore, as observations are most commonly taken from the same year, making the respective studies cross-sectional in nature, the time sensitivity of the conclusions is not investigated.

There are also discrepancies in the CSP measures that are used (reputational ratings, CEP reports or rankings, mention of CSR in annual reports, charitable contributions, Kinder, Lydenberg and Domini database (KLD) ratings, etc.) as well as in the financial risk measures. The latter can be further subdivided into market risk measures (standard deviation of firms' stock returns, stock return beta) and accounting risk measures (e.g. long term debt to assets, debt to equity ratio, volatility of ROA, etc.). Such variation in the operationalization of CSP and CFP greatly diminishes the comparability of results. In response, Orlitzky and Benjamin 
(2001) perform a statistical meta-analysis of these studies using an integrated sample of 6,186 observations and conclude that the true score correlation coefficient $(\rho)$ between CSP and risk is negative. The association appears to be stronger for market risk $(\rho=-0.21)$ than for accounting risk $(\rho=-0.09)$. Furthermore, by testing the temporal sequence, the authors are able to conclude that "the negative correlation between prior CSP and subsequent risk is about twice as large as the correlation between prior risk and subsequent CSP” (p.387).

More recently, the study of Salama, Anderson, and Toms, (2009) provides some evidence on the nature of the link between Community and Environmental Responsibility (CER) rankings and systematic firm risk in the British context. Using cross-industrial UK panel data between 1994 and 2006, leading to a total sample size of 1,625 observations, the authors find a negative and statistically significant relationship between the two variables, with CER being an antecedent of financial risk. However, the sensitivity of the coefficient of this association, as estimated by random-effects GLS regression, is just -0.028 , significant at the $5 \%$ level. This is one of the very few studies of the field where a significantly large set of longitudinal data is employed. However, the authors do not further investigate the dynamics of the CER-firm risk association by attempting to identify possible moderators in the CSPrisk link, such as the possible impact of market volatility conditions. Sharfman and Fernando (2008) strictly focus on the environmental dimension of CSP and show that environmental risk management can effectively lead to a lower cost of equity capital through different pathways, including a lowering of systematic risk and increased tax benefits. The authors only use data from 2001 which makes their analysis cross-sectional.

In addition, Godfrey, Merrill, and Hansen, (2009) build on Godfrey's previous theoretical contribution (Godfrey, 2005) to investigate whether CSP carries insurance-like properties regarding the effect on stock market value of negative firm-specific, rather than 
industry or economy wide, events (p.426). Thus, they conduct an event study analysis upon the negative legal and regulatory actions taken against firms and find evidence that risks are mitigated by CSP but that wealth-protective effects are associated with activities that target a firm's secondary stakeholders, i.e. those who can affect the firm's primary stakeholders, but are not directly essential to the operation of the business. The fine-grained approach of this study, which employs detailed information about events that carry the potential for catastrophic reputational harm for individual companies, is appropriate in the context of the discrete, idiosyncratic type of association between CSP and firm risk hypothesized (Godfrey, 2005). However, the focus upon very specific types of negative events hinders more generalized inferences regarding the wealth-protective effects of CSP activities as total/systematic market risk is generated by not only negative legal and regulatory events but also a host of other sources of uncertainty in the business environment. Similarly, Luo and Bhattacharya (2009) also predominantly look at the effect of CSP on idiosyncratic risk and find the two to be negative related. They do, however, perform some additional analysis which also indicates the existence of a negative association between CSP and systematic firm risk.

In summary, the extant literature on the effect of CSP on financial risk is sparse and problematic, and our study seeks to address a number of the substantive limitations of previous work concerning both the data and methodology employed. We use longitudinal data from the KLD database for S\&P 500 companies between the years 1992 and 2009. This provides a large sample of approximately 7,000 firm-year observations (more than the integrated sample of 6,186 observations pooled by Orlitzky and Benjamin (2001) for their meta-analysis). The great heterogeneity of the sample in both cross-section (more than 760 corporate entities) and time period (18 years of data) facilitates investigation of the variability of the CSP-risk relationship across both industries and time. In the words of Ullman (1985): 
"Longitudinal studies could provide insights into how strategies change as a function of shifting stakeholder power or economic performance." To the knowledge of the authors, this constitutes one of the largest samples ever to be used in the context of the CSP-risk link, as well as in CSP-CFP research as a whole.

In our study, we will employ a wide spectrum of risk metrics that may capture the wealth-protective effects of strong CSP. While standard measures are used for the sake of comparability with previous studies, we also make novel use of downside risk metrics. Furthermore, the addition of utility measures further extends the analysis to incorporate risk, return and higher moments.

\section{Theoretical Background and Development of Hypotheses}

A number of conceptual arguments, mostly emanating from instrumental stakeholder theory (Donaldson and Preston, 1995; Jones, 1995), support a view in favor of the existence of a negative relationship between CSP and financial risk. It could be argued that a company which is consistently socially and environmentally responsible should, in the course of time, obtain the fruits of this strategic posture by experiencing fewer downward adjustments and less volatility in its share price (compared to less socially responsible firms) or, equivalently, that firms having been shown to be involved in controversial, socially and/or environmentally irresponsible activities would be exposed to a higher degree of stock market risk.

High levels of CSP can be associated with low financial risk through, inter alia, lower probabilities of suffering legal prosecutions and fines, less stringent regulatory controls, more stable relations with the government and the financial community (McGuire et al., 1988), 
customer loyalty and a supportive environment on the parts of employees and communities during times of crisis. All of these beneficial implications can lead to reductions of the various operational risks that a company faces in terms of its profitability and overall viability. Also, high firm social performance may be considered to be a sign of superior management skills - the so called "good management hypothesis" (Waddock and Graves, 1997, p.306), thus indicating a firm which is likely to be characterized by more effective business and financial planning and consequently, by improved financial stability. Lastly, there is Godfrey's (2005) rationale, according to which better protection of corporate reputational and relational wealth is achieved by higher degrees of CSP through the generation of mens rea value and positive moral capital that mitigate negative assessments of corporate actions. The first two arguments describe wealth-protective CSP effects of a more generic nature that are likely to shield the firm from the negative impacts of wide ranging, systemic economic shocks while the last one illustrates the risk-reductive effects of CSP in the presence of negative firm related events. We will concentrate on the former types of arguments, recognizing that, as Godfrey et al. (2009) correctly point out "The role of firmspecific characteristics in the face of common events clearly yields illumination" (p.426). Given all of the above, this study is based on the instrumental stakeholder theory framework and as such will attempt to test whether in fact a company that engages in socially responsible (irresponsible) behavior will decrease (increase) its financial risk through that behavior. So ultimately, what is tested is summarized in the following hypotheses.

Hypothesis 1: CSP negatively affects market risk at the firm level.

Due to the complexity in defining and assessing CSP, it is necessary to further clarify what is meant by the term CSP for the purpose of this study. In particular, it is imperative to differentiate between socially responsible and irresponsible corporate activities. The 
multidimensionality of the notion of CSP makes it possible for a company to do well with regards to the societal demands of a particular set of stakeholders (e.g. having good relationships with employees) and less well with regards to others (e.g. being on bad terms with local communities). To rephrase, if CSP is seen as a measure of the moral character of a particular firm then it seems plausible that this company may not be deemed to be purely good or purely bad, but both, according to the focus on particular social issues.

In addition, as McGuire, Dow, and Argheyd (2003) have noted, a firm may be both socially responsible and socially irresponsible even along a single dimension of social performance. For example, according to the KLD STATS dataset, in the year 2000, Exxon Mobil appeared to be a company that had very strong retirement benefits programs for its employees (thus being socially responsible with regards to employee relations) but at the same time had been involved in major controversies concerning workforce health and safety issues (thus being socially irresponsible in the dimension of employee relations). ${ }^{3}$ It is therefore evident that an assessment of the social performance of this firm is not a straightforward task even with a sole focus that is upon a relatively narrowly defined dimension of CSP.

To address this complexity in social performance, we follow the findings of Mattingly and Berman (2006) on the distinction between corporate socially responsible actions and corporate socially irresponsible actions and their conclusion that "positive and negative social actions are both empirically and conceptually distinct constructs and should not be combined in future research" (p. 20). They argue that it is unreasonable to assume that stakeholders will react to responsible and irresponsible behavior in opposite yet symmetrical manners. To make no such assumption, we will refine Hypothesis 1 as follows:

\footnotetext{
${ }^{3}$ The details of this database are discussed in Section III of the study.
} 
Hypothesis 1a: Corporate socially responsible actions and practices lead to reduced levels of firm financial risk

Hypothesis 1b: Corporate socially irresponsible actions and practices lead to increased levels of firm financial risk

Furthermore, there is empirical evidence that corporate social responsibility and corporate social irresponsibility affect a firm's bottom line to differing magnitudes. Wood and Jones (1995) noted in their review that event studies employing market-based measures of CFP show a tendency for poor social performance to inflict financial harm but do not show evidence of a financial boon from strong social performance. Similarly, Meijer and Schuyt (2005) find that while consumers expect a firm's CSP not to fall below some minimum threshold (or else they will boycott), high levels of social responsibility do not bring significantly increased product sales. More recently, it has been shown that "the economic impacts [of CSP] are more positive for issues reducing negative externalities than for issues generating positive externalities" (Lankoski, 2009, p.218). For the KLD rating framework, this means that, ceteris paribus, a firm is likely to improve its economic performance (and decrease the associated firm risk) more if it manages to decrease its social/environmental concerns rather than increasing its respective strengths. Thus:

Hypothesis 2: Social/Environmental strengths are less negatively related to financial risk than social/environmental concerns are positively related to financial risk.

There has also been some debate in the empirical CSP-CFP literature about the appropriate way to handle social performance data, i.e., whether they should be amalgamated into an aggregate, multidimensional measure (Aupperle and Pham, 1989) or if they should be treated as a heterogenous set of corporate actions (Hillman and Keim, 2001). In order to reflect the qualitative variation across the dimensions of CSP - from charitable community 
projects to the adoption of pollution-reduction technology and equal opportunity employment practices, and so on - we will separately analyze each of a number of disparate components of CSP as well as an aggregate measure of performance.

Our use of longitudinal data provides an opportunity to investigate dynamics in the CSP-market risk link, and in particular, examine how this link is moderated in the context of high overall market volatility. In this connection, it is worth noting that Orlitzky and Benjamin (2001) argue that after the burst of the dot.com stock market bubble, investors were more keenly focused upon the underlying risk associated with equity investments and less mindful of capital gains and dividends. More generally, finance and economics literature also suggests a stylized fact that aggregate risk aversion and risk premia change counter-cyclically across time. ${ }^{4}$ If so, one would expect the relationship between CSP and financial risk to be more pronounced during the times of 'lean cows'. In addition, Chen, Guo, and Tay, (2010) suggest that corporations are more likely to implement practices that may reduce firm risk during periods of economic hardship. Thus:

Hypothesis 3a: In the presence of conditions of high market volatility, the association between CSP and financial risk is expected to be stronger than otherwise.

The same line of reasoning also implies that the CSP-risk link should be stronger for investors with higher risk aversion than for more risk tolerant investors. This should be depicted when utility measures are used, since, as risk aversion increases, risk effects tend to prevail over mean return effects. So a more general form of Hypothesis 3 a would be:

\footnotetext{
${ }^{4}$ This is supported by habit formation models for example like those proposed by Abel (1990), Constantinides (1990), Campbell and Cochrane (1999).
} 
Hypothesis 3b: The relationship between corporate social behavior and financial risk will be more pronounced as average investor risk aversion increases.

Having outlined the theoretical background and stated the hypotheses of this study, we proceed to discuss the intuition behind the selection and construction of the variables that are used in the specification of the econometric models.

\section{Independent, Dependent and Control Variables}

\section{A. Independent variables: The KLD database and CSP measures}

Amidst all CSP measures, the ones that stand out are those that are based on what has, with the course of time, become "the best-researched and most comprehensive" (Wood and Jones, 1995) database for social performance: the Kinder, Lydenberg, and Domini (KLD) database. KLD is a rating service which assesses a great number of firms with regard to their strengths and concerns on a series of dimensions of CSP that are considered to be of interest. ${ }^{5}$ To be more specific, companies are rated on multiple indicators within seven "qualitative issue areas" (these being community relations, diversity issues, employee programs, environment issues, product safety and quality, corporate governance, and human rights) as well as six controversial business issues (which examine the extent to which a firm is involved with military contracting, nuclear power, firearms, alcohol, tobacco, or gambling). The rating is done separately on strengths and concerns of the same qualitative issue area while controversial business issues by definition are only rated on concerns. All the ratings are binary, with 1 representing the presence of a particular strength/concern and 0

\footnotetext{
${ }^{5}$ KLD became part of MSCI as from June 2010.
} 
representing its absence. KLD uses sources both internal to the firm (e.g. annual reports) and external (e.g. articles in the business press) to conduct year-by-year assessments of the social performance of 650 firms, including all the firms listed in the S\&P 500 Composite Index and the ones listed in the Domini 400 Social Index. Since 2001, KLD has expanded its coverage universe to incorporate the largest 1000 US companies in terms of market value, an expansion which advanced further in 2003 with the inclusion of the 3000 largest US firms. Independent researchers consistently apply the aforementioned criteria and discuss ambiguous judgments to minimize the subjectivity of the whole process. Given all these advantageous attributes, it constitutes no great surprise that scholars of the field have characterized the KLD dataset as being "the de facto research standard at the moment" for measuring CSP (Waddock, 2003, p. 369). Thus, we elect to use the KLD database and, specifically, KLD STATS (standing for Kinder, Lydenberg, and Domini Statistical Tool for Analyzing Trends in Social \& Environmental Performance) for this study. The core part of our work is centered on the companies listed in the S\&P 500 composite index. The focus of the study on such a widely used benchmark index helps to increase the coverage of firm-year observations by making use of nearly the entire relevant dataset, starting in 1991 and ending in 2008.

Following Hillman and Keim (2001), we concentrate on those qualitative business issues that can be directly associated with specific, primary stakeholder groups and as such may be considered focal for the implementation of successful stakeholder management. In this sense, we disregard the entire set of controversial business issues as being representative of corporate action that Hillman and Keim (2001) deem as "social issues participation". Furthermore, to fully capitalize on the length of the dataset, as well as for the sake of consistency and comparability to previous studies, we only use the omnipresent indicators of each qualitative business issue. This process leads to the selection and utilization of the 
indicators that are depicted in Figure 1. In accordance with the results of Mattingly and Berman (2006) on the taxonomy within the KLD data, we do not combine strengths and concerns of the same issue areas since they appear to be distinct constructs. ${ }^{6}$

We implement the above principles and follow two different ways of combining the KLD data in order to make the most of the information contained in it. Firstly, we attempt to use the individual components of the KLD database. Doing so adds to both the exactness and variability of our conclusions, as it allows us to investigate the relationships between many different facets of the wide spectrum of corporate social action and financial risk. Consequently, we add all the ratings of the indicators for the strength/concerns of a particular qualitative business issue and then divide the sum of those ratings by the number of indicators of the specific issue area. The general formula for calculating any individual component for a particular firm is:

$$
\mathrm{COMP}=\frac{\sum_{i=1}^{n} \text { Respective Indicators' ratings }}{\mathrm{n}},
$$

\footnotetext{
${ }^{6}$ However, we elect not to use the Mattingly and Berman (2006) classification of CSP actions underlying the KLD social ratings data. We do this due to the fact that this classification is tailored to the manner in which CSP outcomes are determined - for example, relatively discretionary behavior influenced by broader institutional positioning on CSR, or operational matters driven by the nature of the core business activities. So, we believe that these categories are not an appropriate fit for our paper because we are focused upon the manner in which CSP is perceived by investors. Given this, there is an imperative to instead employ categories that reflect the way in which different parts of CSP might be differently perceived by external audiences, hence, we split CSP according to the type of corporate social action.
} 
where $\mathrm{n}$ is the number of indicators that are relevant to the particular issue area.

Although the information that can be gained by following the above procedure is valuable, it would be interesting to seek an aggregation of the individual components of social activity that maintains the dichotomy between strengths and concerns. The comparison of the results of a model using an aggregate KLD measure with those of the individual components model would help conclude whether in fact combining various features of social performance to create "a single, monolithic construct" (Godfrey et al., 2009, p.426) dilutes the finer-grained effects of one-dimensional CSP.

In order to create the "Aggregate Strengths" and "Aggregate Concerns" measures, we simply add the respective individual strengths/concerns components which we previously constructed and then divide the sum by five in order for the slope coefficients that will be estimated to be comparable with those of the individual components. The implied assumption is that each type of social action is given equal weighting so that employee programs, for example, are considered just as important as product safety and quality. This is done in accordance with the work of Hillman and Keim (2001) and is due to the lack of conceptual work that would shed light on the effort to quantify the relative importance among the various facets of CSP. Ruf et al. (2001) have tried to address this issue by implementing the Analytical Hierarchy Process (AHP), but the alleged time sensitivity in the assessment of various CSP dimensions - which would require a periodic update of the survey and the implementation of AHP - makes their results unfit for use in this study. Thus, equal importance across CSP dimensions in the construction of the aggregate measure is an unavoidable yet practical compromise. The same logic applies for the equal importance weighting of the various indicators in the construction of each of the individual strengths and concerns components. So the formula for calculating the "Aggregate Strengths" measure is: 


$$
\mathrm{AGGS}=\frac{1}{5} \times(\mathrm{COMS}+\mathrm{DIVS}+\mathrm{EMPS}+\mathrm{ENVS}+\mathrm{PSQS})
$$

where COMS stands for the Community strengths component, DIVS stands for Diversity strengths, EMPS stands for Employment strengths, ENVS stands for Environment strengths and PSQS for Product Safety and Quality strengths. Analogously for "Aggregate Concerns":

$$
\mathrm{AGGC}=\frac{1}{5} \times(\mathrm{COMC}+\mathrm{DIVC}+\mathrm{EMPC}+\mathrm{ENVC}+\mathrm{PSQC})
$$

with the notation being completely equivalent to that of Equation (2).

\section{B. Dependent variables: Financial risk and utility measures}

Picking one measure that captures market risk is not a straightforward task. Financial economists, mathematicians, and risk managers have struggled for decades in order to create new risk metrics with different properties and characteristics. So, to improve the robustness of this study, an array of financial risk measures with different qualities will be utilized. Similarities in results across risk measures will buttress one another while any differences in the conclusions drawn from the use of each measure are likely to shed more light on the strength of the alleged wealth-protective effects of CSP.

Firstly, for the sake of simplicity, comparability with previous research and renewal of the relevant literature with updated information, a classical financial risk measure will be employed, namely the beta of the returns of the firms' shares. It is the most widely used measure of systematic risk and as such is often used instead of standard deviation. ${ }^{7}$ Its calculation is given by:

\footnotetext{
${ }^{7}$ Under traditional portfolio theory (Markowitz, 1991), the total risk that a security bears can be divided into systematic risk arising from broad factors that affect the entire universe of securities and idiosyncratic risk which arises from industry/firm-specific factors. Through diversification, portfolios bearing no idiosyncratic risk
} 


$$
\beta_{\text {im }}=\frac{E\left[\left(R_{i t}-\mu_{i}\right)\left(R_{m t}-\mu_{m}\right)\right]}{E\left[\left(R_{m t}-\mu_{m}\right)\right]^{2}},
$$

where $\beta_{\mathrm{im}}$ is the beta of firm i when the market proxy is $\mathrm{m}, \mu_{\mathrm{i}}$ is the average value of the returns of firm i, $R_{m t}$ is the observed return of the market proxy (S\&P 500) at time $t$ and $\mu_{m}$ is the average value of those returns.

In addition to the use of the aforementioned metric, this study makes an original contribution to the CSP-CFP literature with the introduction of downside risk measures. ${ }^{8}$ The motivation for the use of these measures arises from several factors. Firstly, conventional risk measures like beta are appropriate when the distributions of the returns of the assets under consideration are symmetric (such as in the case of a normal distribution). In this situation, standard risk measures (SRMs) and downside risk measures (DRMs) will produce the same results. However, when the distributions of returns are asymmetric (DeFusco, Karels, and Muralidhar, 1996) then either the downside price fluctuations will have a dominating effect over the upside or the other way around. Specifically, if the distribution of returns is negatively skewed or "skewed to the left" (so that skewness is smaller than 0), SRMs underestimate risk because they underestimate the proportion of extreme negative deviations from expectation, which are the true source of anxiety for the investor. Since SRMs and DRMs will generate different measurements of financial risk and since it seems more intuitive to think of financial risk as the probability of a downward movement (rather that a

can be constructed so that the investor is only compensated for the market risk of his investments. That is why it is argued that only the systematic risk of a security matters and, hence, this study employs beta as a measure of financial risk rather than standard deviation.

${ }^{8}$ Luo and Bhattacharya (2009) mention the existence of models that use downside equity betas but do not use such a model in their study. 
general price instability), DRMs are more appropriate. Secondly, it has been argued that "losses and disadvantages have greater impact on preferences than gains and advantages" (Tversky and Kahneman, 1991 p.1039), a sort of loss aversion utility theory, with the implication being that investors are more sensitive towards downside risk and are thus likely to require a significant premium for their exposures in assets with downside risk.

These first two arguments are valid whether we refer to the context of the financial effects of CSP or not. A more well-focussed argument in favor of the use of DRMs is that they are especially compatible with Godfrey's (2005) arguments about the insurance effects that CSP will have on CFP. Following this line of reasoning, financial risk should be depicted as the likelihood of a downward adjustment in the stock prices of socially irresponsible firms instead of a general instability and variability of those prices.

The measure of downside risk that will be applied is downside beta. It must be noted that there is no consensus in the financial literature about what is the most appropriate definition, and subsequently method for estimation, of the downside beta. The main issue in question is the minimum threshold that a market participant should use to evaluate the returns of the asset he has invested in. Risk will then be characterized by the downside deviations from this target. We consider two of the downside betas proposed in the literature.

The first comes from the work of Bawa and Lindenberg (1977), who use the risk free rate as the target return and the second is that introduced by Harlow and Rao (1989) who instead use the mean market return as a threshold. The respective formulae are:

$$
\begin{gathered}
\beta_{\mathrm{im}}^{\mathrm{BL}}=\frac{\mathrm{E}\left[\left(\mathrm{R}_{\mathrm{i}}-\mathrm{R}_{\mathrm{f}}\right) \min \left(\mathrm{R}_{\mathrm{m}}-\mathrm{R}_{\mathrm{f}}, 0\right)\right]}{\mathrm{E}\left[\min \left(\mathrm{R}_{\mathrm{m}}-\mathrm{R}_{\mathrm{f}}, 0\right)\right]^{2}}, \\
\beta_{\mathrm{im}}^{\mathrm{HR}}=\frac{\mathrm{E}\left[\left(\mathrm{R}_{\mathrm{i}}-\mu_{\mathrm{i}}\right) \min \left(\mathrm{R}_{\mathrm{m}}-\mu_{\mathrm{m}}, 0\right)\right]}{\mathrm{E}\left[\min \left(\mathrm{R}_{\mathrm{m}}-\mu_{\mathrm{m}}, 0\right)\right]^{2}},
\end{gathered}
$$


where $R_{i}$ and $R_{m}$ are the returns on security $i$ and the market portfolio, respectively, $\mu_{i}$ and $\mu_{\mathrm{m}}$ are the mean returns of security $\mathrm{i}$ and the market portfolio, respectively and $\mathrm{R}_{\mathrm{f}}$ is the risk free rate (3 month T-Bill rate).

Until this point, we have focused solely on the risk connected to the second moment of returns (although the DRMs that we mentioned correct the biases in the measurement of risk that may be incurred due to high negative values of the third moment). An examination of the higher moments of the distribution of asset returns would significantly enrich the analysis by allowing a more in-depth assessment of the nature of the effects of CSP on financial risk. For example, it may be that specific types of social and environmental firm actions that produce positive (negative) externalities affect the skewness of the distribution of its stock returns and tilt the distribution to the right (left). Or that a firm that is characterized by particularly mixed social performance (e.g. scoring high on both strengths and concerns on various business issues) may have a more leptokurtic distribution of stock returns, as there is an increased probability of extreme results occurring, either positive or negative. Additionally, the inclusion of the mean return in a utility measure may provide hints regarding the extent to which the magnitude of the alleged risk-reduction effects of CSP is offset by a proportionate reduction in asset returns.

To test the effect that CSP has on investors' utility, we apply the extension of the mean-variance criterion to higher moments. This criterion has many advantageous characteristics. It can be applied when an investor's utility is described by the negative exponential utility function, one of the most widely used such functions. Furthermore, and in contrast to the mean-variance criterion, one does not need to additionally assume distributional normality of returns in order to use the criterion's extension to higher moments. In fact, it is not even necessary for the distribution of returns to be symmetric or mesokurtic 
since the criterion explicitly incorporates the third and fourth moments of the distribution, a highly desirable property which allows for non-parametric empirical applications. The fourth order approximation of the certainty equivalent ${ }^{9}$ that is associated with the negative exponential utility function is given by the formula:

$$
C E \approx \mu-\frac{1}{2} \gamma \sigma^{2}+\frac{\tau}{6} \gamma^{2} \sigma^{3}-\frac{\kappa}{24} \gamma^{3} \sigma^{4}
$$

where $\mu$ is the mean, $\sigma$ is the standard deviation, $\tau$ is the skewness, $\kappa$ is the kurtosis of the asset returns and $\gamma$ is the investor's absolute risk aversion. We will interchange between using $\gamma$ values of 2,5 , and 20 in order to capture a very wide range of investor preferences. It should also be noted that this measure does not incorporate the non-financial utility that some investors may derive from investing in firms with high CSR standards (Renneboo, Ter Horst, and Zhang 2008b) since this study is restricted to examining the effects of CSP on financial risk and economic utility.

\section{Control variables}

This subsection describes the series of variables that are used in the model specifications in an effort to remove the impact of non-CSP factors and, accordingly, to zoom in on the effects of CSP variables on financial risk per se. Furthermore, this set of variables is employed in order to ensure as far as possible that the effect of CSP on firm financial risk is not spurious and merely the artifact of an omitted variable bias.

\footnotetext{
9 The monetary amount that has the same utility as the expected utility of an uncertain investment.
} 
i) Size: Ln(Market Value). Larger firms are generally thought of as being less risky than smaller firms. This seems to be a sensible statement especially if one considers the firms' probabilities of default. Large firms are inherently more competent in enduring adverse economic shocks. Furthermore, it has been argued that firm size is proportionally negatively related to asset return variance (Beaver, Ketter, and Scholes, 1970, p.662) and that reputational effects are higher for larger firms, thus making banks view them as less risky and reduce the yields that they charge them (Diamond, 1991). Following the norm, the logarithm of firm size, as captured by stock market capitalization, is used to correct for the skewness of the measure.

ii) Market to Book Value (MTBV) ratio. Due to a significant number of missing values in the Datastream database, we construct a proxy for this ratio by dividing firm market value by the respective book value of common equity. As Fama and French (1992) note in their seminal work on the cross-sections of expected stock returns, it is possible that the reciprocal of MTBV captures risk which is associated with the distress factor of Chan and Chen (1991). Specifically, it is argued that companies the market deems to have poor prospects are characterized by lower stock prices and higher book to market ratios (lower MTBV ratios) than companies with stronger prospects (p.428). However, these stronger prospects may lead to greater variability in profitability and capital market performance. This "growth vs. value" differentiation of firms may explain why analysts often consider the stock of a company with low MTBV to be a less risky investment, with book value seen as the minimum threshold of firm equity.

iii) Gearing: Total Debt to Common Equity (TDCE) ratio. Again, instead of directly using a gearing measure, we prefer to construct this proxy in order to avoid having a multitude of missing observations for this variable. An excessively high ratio of financial 
leverage indicates significant indebtedness which may lead to a firm's difficulty in meeting the demands of its creditors and as such, worsen its viability. In addition, the classic study of Modigliani and Miller (1958) shows that the higher a firm's debt, the higher the volatility of the earnings stream towards its stockholders which is why "the expected rate of return ... on the stock of any company... is a linear function of [its] leverage” (p.271).

iv) Dividend Yield. Dividend yield on a company stock is the ratio of the dividend per share to the price per share of that stock. Although there is no consensus in the relevant literature, there is evidence which suggests that stocks having higher dividend yields are also characterized by higher risk adjusted total returns than stocks paying no or low dividends (Blume,1980). Arguably, a constant, high expected flow of dividends is likely to reduce the volatility and systematic risk of stock prices due to duration and information effects. ${ }^{10}$ Also, dividend yield can be thought to have a signaling effect regarding management's perception of the uncertainty of future earnings (Beaver et al., 1970, p.660) i.e. the higher the dividend yield the less the uncertainty and vice versa.

v) Research and Development (R\&D) intensity: R\&D Expenditure to Total Sales ratio. McWilliams and Siegel (2000) present evidence which supports the position that a significant part of the CSP-CFP literature is based on mis-specified models, since the R\&D expenditure is not included. This variable has been found to be an important determinant of firm performance, and is argued to also be positively correlated with CSP, as CSP is thought of as a stream of product and process innovations which are generated by $R \& D$ expenditures. The attempt to create such innovations constitutes an inherently risky project. Because of

${ }^{10}$ The term "duration effect" is used to imply that high dividend yield provides more cash flow in the short term. If dividend policy is assumed to remain stable then high dividend stocks will have a shorter duration. 
this, the exclusion of this variable may lead to an omitted variable bias as discussed above, which results in biased and inconsistent coefficient estimates.

vi) Liquidity: ${ }^{11}$ Current ratio. The current ratio is calculated by dividing a firm's book value of current assets by that of its current liabilities. It is indicative of the firm's ability to remain solvent in the short run. The current ratio is one of the ratios most widely used to assess a firm's liquidity risk. Obviously, the lower the current ratio, the higher the liquidity risk for a company, a feature which may be depicted by increased stock price fluctuations for that firm.

vii) Industry classification. We use the Industry Classification Benchmark (ICB) at its second level of analysis, i.e., a taxonomy of companies according to supersectors. This results in the construction of a total of 19 industry dummy variables. These are: Oil \& Gas, Chemicals, Basic Resources, Construction \& Materials, Industrial Goods \& Services, Automobiles \& Parts, Food \& Beverage, Personal \& Household Goods, Health Care, Retail, Media, Travel \& Leisure, Telecommunications, Utilities, Banks, Insurance, Real Estate, Financial Services, and Technology. The inclusion of these dummy variables seems appropriate given the inherent variability in the risk attributes across supersectors. However, as the analysis is restricted to US firms, there is no need to include control variables for country effects.

\footnotetext{
${ }^{11}$ Note that during this discussion we have used the term "liquidity" to refer to a firm's funding liquidity and not to the liquidity of the market where the firm's stock is traded, the latter being an irrelevant issue in the case of the very actively traded, highly liquid S\&P 500 stocks of this sample. Funding liquidity is defined as a firm's ability to settle obligations with immediacy and the respective risk is driven by the possibility that over a specific horizon a firm will become unable to settle obligations with immediacy (Drehmann and Nikolaou, 2009, pp.10-11). Market liquidity is defined as the ability to trade large size quickly, at low cost, when you want to trade (Harris, 2003, p.394).
} 


\section{Methodology}

\section{A. Sample construction}

As has been already stated, our initial sample consists of all the companies listed in the S\&P 500 Composite Index and rated by KLD on their corporate social performance at some point(s) during the period between 1991 and 2008. This translates to an unbalanced panel dataset of 9,000 firm-year observations. KLD STATS provides the names and tickers of the companies it rates and since 1995 also uses their respective CUSIPs but unfortunately has never used Datastream codes. There are several roundabout ways to match the year by year list of S\&P 500 companies with their Datastream identifying codes but all of them lead to a great loss of firm-year observations and they bear the additional risk of including the wrong type of stock for those companies that are listed on several exchanges. To avoid such hazards, a methodical, manual scrutinization and subsequent matching of each firm to its respective Datastream code was conducted on a one-by-one basis. When a firm's stock was traded on several exchanges, the code of the stock being traded at the main stock exchange was used, when such an indication was available, or else the firm was dropped from the sample. Preferred stocks were also dropped from the sample.

Overall, for the estimation of our basic models, a series of variables that have been mentioned in Section III had to be used. For the construction of the various financial risk and utility measures, we calculated the weekly log-returns of the prices of the Total Return Index (TRI, Datastream code: RI) for each share. ${ }^{12}$ For the calculation of the beta factor and the downside beta metrics, a market proxy had to be used. The obvious choice, given the dataset,

\footnotetext{
${ }^{12}$ The TRI assumes the reinvestment of distributed dividends so that both pure capital gains and dividend payouts are included in the calculation of stock returns.
} 
was the S\&P 500 itself (Datastream code: S\&PCOMP). We also gathered data for all the control variables that we employed. ${ }^{13}$ After dropping all firm-year observations for which at least one of the variables needed is missing, our sample consists of 6,986 firm-year observations (a total of $N=769$ different firms over a period of $\mathrm{T}=18$ years). ${ }^{14}$

\section{B. Model specification}

As has been thoroughly explained in the previous section of the study, we estimate three types of models, each offering a different piece of information regarding the relationship between CSP and financial risk. The first one is the "individual components" model:

$$
\mathrm{RM}_{\mathrm{it}}=\alpha_{\mathrm{i}}+\sum_{\mathrm{j}=1}^{10} \beta_{\mathrm{j}} \mathrm{COMP}_{\mathrm{jit}-1}+\beta_{11} \mathrm{MV}_{\mathrm{it}-1}+\beta_{12} \mathrm{MTBV}_{\mathrm{it}-1}+\beta_{13} \mathrm{DY}_{\mathrm{it}-1}+\beta_{14} \mathrm{TDCE}_{\mathrm{it}-1}+\varepsilon_{\mathrm{it}}
$$

where $\mathrm{RM}_{\mathrm{it}}$ is the risk or utility measure for firm $\mathrm{i}$ in year $\mathrm{t}, \alpha_{\mathrm{i}}$ is the time invariant intercept for firm i, $\beta s$ are the slope coefficients of the respective factors, $\mathrm{COMP}_{\mathrm{jit}-1}$ is the individual component $\mathrm{j}$ (strengths and concerns of the five qualitative issue areas of interest: community relations, diversity issues, employee programs, environment issues, product safety and quality), $\mathrm{MV}_{\mathrm{it}-1}$ is the market capitalization, $\mathrm{MTBV}_{\mathrm{it}-1}$ is the market to book value ratio, $\mathrm{DY}$ it-

\footnotetext{
${ }^{13}$ Note that the core models do not include R\&D intensity and liquidity as control variables. These factors are added later as robustness checks. As a result, the filtering process mentioned here does not concern these two variables.

${ }^{14}$ We choose to use this unbalanced panel of data rather than extracting a balanced subpanel from it, by either maximizing the number of firms observed (restricted maximization in the cross-sectional dimension) or by maximizing the average number of observations per firm (restricted maximization in the time series dimension) because either of these methods would lead to a huge loss in efficiency (Baltagi and Chang, 1994).
} 
${ }_{1}$ is the dividend yield, $\mathrm{TDCE}_{\mathrm{it}-\mathrm{1}}$ is the total debt to common equity ratio, all referring to firm $\mathrm{i}$ in year $\mathrm{t}-1$, and $\varepsilon_{\mathrm{it}}$ is the respective disturbance term. ${ }^{15}$

The second model is the "aggregate strengths/concerns" model:

$$
\mathrm{RM}_{\mathrm{it}}=\alpha_{\mathrm{i}}+\beta_{1} \mathrm{AGGS}_{\mathrm{it}-1}+\beta_{2} \mathrm{AGGC}_{\mathrm{it}-1}+\beta_{3} \mathrm{MV}_{\mathrm{it}-1}+\beta_{4} \mathrm{MTBV}_{\mathrm{it}-1}+\beta_{5} \mathrm{DY}_{\mathrm{it}-1}+\beta_{6} \mathrm{TDCE}_{\mathrm{it}-1}+\varepsilon_{\mathrm{it}},
$$

where the notation for most terms is identical to that of equation (8), $A G G S_{i t-1}$ is the measure of aggregate CSP strengths (Equation (2)) and $\mathrm{AGGC}_{\mathrm{it}-1}$ the measure of aggregate CSP concerns (Equation (3)) for firm i in year t-1.

For every model, a variety of risk/utility measures will be used (beta, downside risk metrics plus the extension of the certainty equivalent to higher moments for different values of absolute risk aversion), resulting in multiple estimations. In all models, the independent variables are lagged. This is done for several reasons. Firstly, it has been clearly stated that this study is oriented towards the examination of a relationship between CSP and market risk where CSP is the cause and subsequent levels of firm risk are the effect. Furthermore, lagging the CSP measures and control variables helps this study escape the alleged endogeneity problems and simultaneity bias that may arise due to a contemporaneous bidirectional causality of CSP and risk. Also, as the manual of KLD STATS reveals, although the data collection process and appraisal of firm social performance is an ongoing, continuous process, KLD actually assembles the data at the end of each calendar year, and compiles the data into the spreadsheets at the beginning of the next year (pp. 4-5). So, following the rationale of Godfrey et al. (2009), lagging our social/environmental variables by one year helps to "ensure that the ratings for each firm were public knowledge" (p.434) and so had

\footnotetext{
${ }^{15}$ The fixed effects estimation model is applied and its details will be discussed in subsection C.
} 
already started to become incorporated by the markets in the form of informative prices. Hence, when we use CSP measures from year t-1, we start collecting stock price data from the second week of year $t$ to calculate the respective risk/utility metrics.

In addition, in order to avoid including in the analysis outliers that may heavily influence the results, all the risk and utility measures along with the financial control variables are winsorized at the $1 \%$ level. ${ }^{16}$ This is important since firm-year observations that are characterized by extremely high volatility are likely to sway the goodness of fit of the model towards their direction.

\section{Panel data econometrics}

Choosing the correct panel data regression model is crucial in empirical analysis. The efficiency and consistency of the estimated intercepts and slope coefficients is dependent on the choice of the appropriate estimator, each having characteristic properties. The first choice the researcher has to make concerns the selection of a fixed or random effects model. Given the fact that this study is restricted to large, American, publicly traded firms that have been included in the S\&P 500 Composite Index, the fixed effects model appears to be the most intuitive option because as Baltagi (2005) notes: "The fixed effects model is an appropriate specification if we are focussing on a specific set of $N$ firms ... and our inference is restricted to the behavior of this set of firms" (p. 12). The random effects model on the other hand is

\footnotetext{
${ }^{16}$ Winsorization is a transformation process in which the values of outliers are replaced by a specific threshold value (in this case, the bottom and top $1 \%$ of the observations are replaced by the 1st and 99th percentile of the relevant empirical distribution respectively). In addition, pooled quantile regressions are also estimated and verify the robustness of the analysis to outliers.
} 
preferred when the firms of the dataset are assumed to represent random draws from a larger population (Baltagi, 2005, p.14), which is not the case in this instance. In addition, estimating models (8) and (9) using random effects and performing Hausman tests produces results that strongly support the use of fixed effects in the estimation. ${ }^{17}$ Another possible method to use is pooled ordinary least squares (OLS). This approach is the most restrictive of the methods as it specifies constant coefficients for both intercepts and slopes (whereas fixed effects, for example, specifies constant slope coefficients but allows the intercepts to be different between firms). The pooled OLS estimator is inconsistent when the fixed effects estimator is appropriate (Cameron and Trivedi, 2005, p.699). Performing likelihood ratio redundant fixed effects tests results in a strong rejection of the null hypothesis that these effects are redundant. So the pooled OLS method is inappropriate.

Given the above discussion, it appears that the fixed effects estimators are the most appropriate to use in this study. The notation of Equations (8) and (9) has taken this factor into account, which is why the intercept term is $\alpha_{i}$, indicating that it varies across firms but is time invariant. Notice that in all equations, the set of industry dummy variables is not explicitly used in the specification because this piece of cross-sectional heterogeneity is constant over time (assuming that a company does not significantly alter its business orientation) and as such is captured by the intercepts.

Another issue of importance when dealing with panel data sets is the estimation of robust standard errors. If the residuals of the model for a given firm are correlated across years (time-series dependence) or the residuals for a given year are correlated across firms (cross-sectional dependence) then the standard errors of the estimated coefficients will be upward or downward biased. In the latter case, the statistical significance of the results of the

\footnotetext{
${ }^{17}$ Results are not reported but are available by the authors upon request.
} 
study will be overestimated and the conclusions drawn may be invalid. Indeed, a lot of studies in the finance literature have either completely ignored this issue or have addressed it in an inappropriate manner (Petersen, 2009, pp.435-436). Recognizing the implications of this matter, a significant effort is made to effectively tackle it.

There is reason to expect that time-series dependence may arise in the residuals of the models since CSP is usually relatively constant for the same firms and social/environmental dimensions across time. Persistence in the application of CSR principles appears the most reasonable way to ensure the accruement of its long-run beneficial economic impacts. Taking a look at the bar schematics of the various CSP components (both strengths and concerns) for the individual cross-sections (firms) reinforces this expectation: The vast majority of firms have ratings that are persistently high or persistently low throughout the years. The inclusion of fixed effects (dummy variables) in the specified models deals with this issue and leads to unbiased standard errors, as long as this time-series dependence is fixed and not timedecreasing (Petersen, 2009, p.464). On the other hand, there are no particular grounds to anticipate that cross-sectional dependence will arise in the residuals of the fixed effects model. Furthermore, the detection of such dependence is not a straightforward process considering both the two-dimensional nature of the residuals and the fact that the crosssections are randomly (alphabetically) stacked. As a rule of the thumb, Breusch-Godfrey serial correlation LM tests on the cross-sectional samples (year by year) are performed and do not, on the whole, provide significant indications of the existence of cross-sectional dependence. ${ }^{18}$ Following the same rationale, performing White's heteroskedasticity tests in

\footnotetext{
${ }^{18}$ With three different models, many different dependent variables that are alternatively used for each model and 18 different years, there are several hundreds of such tests that are
} 
the cross-sectional, year-by-year samples provides evidence of cross-sectional heteroskedasticity in the residuals. To account for this, the diagonal White cross-sectional heteroskedasticity robust coefficient covariance estimator (adjusted for panel data) is applied. Henceforth, and unless otherwise noted, all the t-statistics reported will be the outcome of the implementation of the above processes which should lead to the estimation of robust standard errors.

\section{Results}

\section{A. Descriptive statistics and correlations}

Tables I, Panels A, B, and C present the descriptive statistics of the various independent and dependent variables that are specified in the core models of the study. The statistics refer to the winsorized financial variables that are used to remove significant outliers from the distributions of the risk and utility measures and the control variables. According to the statistics provided in Table I Panel A, the mean values for each of the individual component CSP measures are small, ranging between 0.0371 (Community concerns) and 0.1253 (Product concerns). The low mean values, combined with the zero median values of all measures, indicate that for the majority of firm-year observations, the most frequent score in each CSP dimension is zero (indicative of the absence of the respective strength or concern). It should also be noted that, by construction, each component can only take specific discrete values within the $[0,1]$ range. For example, Community strengths can take a value of $0,0.25$, $0.50,0.75$, or 1 depending on how many of the four respective indicators are present for a particular firm in a specific year according to KLD. Standard deviations of KLD scores are

performed. The vast majority of them result in very high $p$-values (much above 0.10 ), indicating high levels of support for the null hypothesis of no correlation of the residuals. 
also similar amongst individual components. It is worth noting that Community strengths has both the smallest mean and the smallest standard deviation (0.0970) while Product concerns has both the highest mean and the highest standard deviation (0.1999). Aggregating across CSP dimensions, one can see in Table I Panel B that the mean and median scores are very similar, a bit higher for strengths (mean of 0.0786) than for concerns (mean of 0.0743 ) but with the variability of concerns scores being higher than that of strengths (0.0926 against $0.0775)$.

The average winsorized value of the logarithm of firm market value is $8.91 .^{19}$ The average firm-year observation also has a MTBV ratio of 3.70, a dividend yield of $1.89 \%$ and a leverage ratio of 1.38. As for the dependent variables, one can notice in Table I Panel $\mathrm{C}$ that the average values of all beta measures are very close to unity, as they ought to be. They do not exactly equal one, for the simple reason that this is an unbalanced panel of data. Lastly, the mean utility measures are negative and algebraically lower as risk aversion increases, with the interpretation being that, on average, any positive utility effects coming from reaping positive returns are increasingly offset by the respective values of the volatility of returns. ${ }^{20}$

The first two panels of Table II provide some additional interesting statistics. Table II Panel A contains Pearson product-moment correlations between the various individual social/environmental components as well as the aggregate measures. By construction, aggregate strengths (concerns) are highly positively correlated to uni-dimensional strengths (concerns). What is interesting is the fact that, overall, there are small but positive correlations amongst social strengths and concerns, thus reinforcing the opinion that strengths and concerns are distinct constructs that should not be mixed in empirical research as they do

\footnotetext{
19 Market value is reported in thousands of dollars.

${ }^{20}$ Assuming that the negative exponential utility function is appropriate.
} 
not constitute the flip sides of the same coin. Also, the correlations between individual components are small in absolute value, so near multicollinearity issues are not expected to arise in the estimation of model (8). Furthermore, as was expected, there are high but not perfect positive correlations between the conventional risk metrics and their downside risk analogues (Table II Panel B). This indicates that they capture slightly different characteristics of market risk. Also intuitive is the fact that the utility measures are moderately negatively related to the risk metrics (which should be the case according to Equation (7)) and highly positively correlated for different levels of risk aversion.

Table II Panel C displays the mean values of the individual component measures for each super-sector, and shows cross-sector variation that is broadly consistent with expected tendencies for certain social/environmental issues to be more salient in some industries and less so in others. In particular, in industries where employees are subject to relatively intensive and hazardous workplaces and working practices (such as Automobiles, Basic Resources, Construction materials, Oil \& Gas, Telecoms, Industrial goods) we observe high scores either in terms of KLD strengths or concerns or both. Environmental issues, on the other hand, have higher mean values in sectors for which pollution and other environmental impacts are relatively focal issues: Automobiles, Basic resources, Chemicals, Construction Materials, Utilities, Oil \& Gas, and Industrial goods. The Product safety/quality and Community dimensions appear to be most prominent in those supersectors where it is beneficial for the firm to establish long-term relationships with customers built upon a corporate image and brand name that speaks of commitment, security and stability (such as Banking (Turnbull and Gibbs, 1987), Financial Services, Insurance, and Telecoms).

In this connection, it is also worth noting the tendency for relatively high mean values for both strengths and concerns to be found in a single sector at the same time. For example, 
the Automobiles, Basic Resources, and Chemicals industries have scores that surpass the cross-industrial sample averages in both Environmental strengths and concerns. The same applies for the Telecoms, Travel \& Leisure, and Automobiles supersectors regarding Diversity issues. The simultaneous prevalence among a given set of firms of strengths and concerns in a single dimension of CSP raises the possibility that firms commonly act from an imperative to reduce social harm that results from their business activities - motivated by a genuine sense of social responsibility or by a desire to ingratiate the firm with stakeholders that might otherwise view the firm as irresponsible and react accordingly. Moreover, the observation that CSP is not reflected in the presence of strengths or concerns but rather in a mixture of positive and negative indicators, ensures that a single, aggregate measure of CSP would overlook this considerable complexity. As we employ separate measures of strengths and concerns, we avoid this loss of information.

\section{B. Main results}

The estimated values of the averaged fixed effects and slope coefficients of the "individual components model" are provided in Table III. Each column of Table III represents a different estimation of model (8) with the dependent variable (alternative risk or utility measure) listed at the top of each column. Overall, there appears to be a negative but insignificant relationship between the various corporate social strengths and systematic financial risk. Not a single slope coefficient between any of the five strength components and any of the betas has a t-statistic with an absolute value greater than 1.6449 (the approximate critical value at the $10 \%$ level of significance for a two-tailed test). The results are very similar when certainty equivalents of stock returns are used as dependent variables, with the findings being largely insignificant, the exception being employment strengths which are negatively associated with investor utility for average and high levels of risk aversion. This 
last finding could be rationalized by observing that some of the indicators of employment strengths have a financially ambiguous nature since they lead to immediate costs for the company with the expectation of medium- to long-term economic benefits. For example, significant cash profit sharing and strong retirement benefits are characteristically supportive of this line of reasoning (and both are used by KLD, as can be seen in Figure 1). Such practices are obviously costly for the firm but are expected to cause an easier attraction of superior quality employees, higher personnel retention ratios, decreased costs of staff training and improved employee loyalty. This result is also in contrast to the conclusions of Edmans (2011), who found a positive relationship between employee satisfaction and risk adjusted returns. However, Edmans (2011) uses the "100 Best Companies to Work for in America" as his CSP measure (which does not escape the criticism of halo effects) and risk adjusted returns as a performance metric which makes the results of the two studies somewhat incomparable. $^{21}$

When looking at the lower half of Table III, it is noticeable that the link between the individual concerns components and risk is stronger than the respective link between their strength counterparts and market risk. Community, Employment, and Environment concerns are all significantly positively related to systematic risk (slope coefficients of $0.1622,0.1906$, and 0.1680 , respectively). Not only that, but these coefficients are much greater than most of the estimated coefficients between the array of risk metrics and social/environmental strengths. This observation provides strong support for Hypothesis 2, which stated that the effect of CSP concerns on financial risk would have a greater impact than that of CSP strengths and is in accordance with Lankoski's (2009) findings that the economic impacts

\footnotetext{
${ }^{21}$ Meaning that it is possible that this type of measure captures financial success rather than CSP, to some extent, thus it is expected that the study will reveal a positive CSP-CFP link.
} 
were more positive for CSP issues that reduce negative externalities (KLD concerns in this case) than for those that generate positive externalities (KLD strengths in this study). This weak negative (moderate positive) association between the individual KLD strength (concern) components and financial risk verify the findings of the Salama et al. (2009) study that focuses on a longitudinal data sample of firms from the UK. The results are also consistent with those of previous research with the same purpose but very different datasets and methodologies, such as Spicer (1978), Aupperle et al. (1985), McGuire et al. (1988), Orlitzky and Benjamin (2001). Focusing on utility measures, most of the results are statistically insignificant, but Employment concerns are significantly negatively associated with certainty equivalents, indicating that while implementing socially responsible practices towards employees may be excessively costly, being socially irresponsible in the same respect may lead to decreased levels of investor utility.

Moving on to Table IV, which presents the output of the estimation of model (9), there appears to be a statistically significant negative association between the aggregate measure of social strengths and firm beta (equal to -0.2938 , significant at the $5 \%$ level) and a positive relationship between aggregate concerns and all risk metrics applied (slope of 0.3629 for beta and 0.3760 for the Harlow and Rao downside beta, both significant at the $1 \%$ level). The fact that an array of risk metrics verifies the positive relationship between risk and aggregate CSP concerns, but the same does not happen for aggregate strengths further reinforces hypotheses $1 \mathrm{~b}$ and 2 . Also, since the statistically significant estimated slope coefficients are of either similar or greater absolute value than those of the individual component models, it appears that the effect of CSP on market risk is not necessarily better captured when disaggregated measures of social performance are used. However, all the results of the "aggregate models" that use utility measures as dependent variables are statistically insignificant, a finding that enhances the idea that disaggregate data may prove to 
be more useful in relevant research, as "various aspects may have differential impacts depending on the nature of the firm's business" (Brammer, Brooks and Pavelin, 2006, p. 103). Overall, the financial risk impact of corporate social performance is not masked when the aggregate measures replace the individual components, so the rationale of Godfrey et al. (2009) that a multidimensional measure of social performance will likely conceal the wealthenhancing effects of disaggregated CSP aspects is not verified in this case. ${ }^{22}$

In both models, the goodness of fit statistics are very similar for the same dependent variables. The adjusted $R$-squares of the models using risk measures range from approximately $27 \%$ (for the Bawa and Lindeberg beta) up to approximately $35 \%$ (for beta) and all compare favorably to the Salama et al. (2009) estimations of $R$-squares equal to $11.5 \%$ for the fixed effects regression and $24.3 \%$ for the random effects regression as well as to the McGuire et al. (1988) results that are characterized by $R$-squares of $13.1 \%$ for the total market risk model and $17.5 \%$ for the systematic risk model. The adjusted $R$-squares are smaller when utility measures are applied, as these models appear to explain, at a maximum, approximately $26 \%$ of the variability of investor utility (for a moderate level of absolute risk aversion equal to 5).

\section{Moderating effects of volatility conditions}

During the development of the hypotheses that this study examines, it was stated that the overall volatility of the stock market may be an important moderating factor in the

\footnotetext{
${ }^{22}$ Tables III and IV do not include slopes for the R\&D intensity or liquidity measures. These control variables are later added to test the robustness of the models. Many firms in the Datastream database have missing values for $R \& D$. We set $R \& D$ expenditures equal to zero when the value is missing, following Benson, Davidson, Wang, and Worrell, (2011). In addition, because of the different capital structures between firms operating in sectors with fundamentally dissimilar characteristics, alternative measures of financial leverage are used in the specifications of the basic models. Specifically, the total debt to common equity ratio is interchanged with the total debt to total sales and total debt to total assets ratios. Overall, the signs, values and statistical significance of the estimated coefficients as well as the goodness of fit statistics are remarkably close to those of the original specifications. Results are not reported but are available from the authors.
} 
relationship between CSP and financial risk. To test this assertion, the panel data sample was split into two smaller subsamples according to the average level of stock returns volatility for a yearly period. Figure 2 clearly shows that average annualized weekly volatility remains within a range between $24 \%$ and a little more than $37 \%$ for most years of the sample but spikes up to a range between $44 \%$ and approximately $56 \%$ for the periods $2000-2002$, attributable to the burst of the "dot.com" bubble, and 2008-2009, when the downturn in the US real estate market lead to a global economic crisis. So firm-year observations from these two periods are stacked together and then structured appropriately in the same way that the original sample was.

Table V presents the estimation of Equation (8) for the "high volatility" sample. The statistically significant results are once more very similar to those produced by the core analysis of the initial sample, revealing a positive relationship between Employment/Environment concerns and financial risk. The slope coefficients between these concerns components and the various risk measures are often two times, or more, greater than those estimated when the entire longitudinal sample was used. For example, when beta is treated as the dependent variable, the slope coefficients estimated in the initial analysis are 0.1906 for Employment concerns and 0.1680 for Environment concerns while the respective values for the "high volatility sample" are 0.3395 and 0.3174 , respectively. No significant results are found when utility metrics are used as dependent variables and as such the relevant estimates are not reported. The results of the estimation of model (8) when the "low volatility" sample is used are provided in Table VI. The picture is now very different. It is the strengths components that produce more pronounced results, with Diversity and Employment being significantly negatively related to risk (across both conventional and downside risk measures), while concerns produce results that are less significant and more randomly 
distributed across the various risk metrics models. Community and Environment concerns show some signs of significant positive association with the various betas.

When these results are jointly taken into account, it appears as if, especially in times of financial distress, social and environmental corporate concerns are priced by the market and lead to higher levels of stock price volatility for companies that 'do wrong', while in times of economic euphoria, or at least times of no significant general economic hazards, the importance of CSP strengths becomes more pronounced and is able to decrease the levels of a firm's stock market risk. To put it differently, these results seem to provide evidence that the market encourages a "slack resources" type of firm behavior (Waddock and Graves, 1997) during good times as CSP strengths have stronger wealth-protective effects then. On the other hand, the market appears to concentrate more on CSP concerns during bad times, when it penalizes the companies that are being socially irresponsible more severely through higher financial risk.

It should also be noted that the adjusted $R$-squares of the estimated models for the high volatility periods are all considerably higher compared to those of the regressions of the original sample with a range between $40.9 \%$ and $50.6 \%$ when risk is used as a dependent variable. The fact that the usual winsorization process is applied to the dataset before the model estimations are made helps to ensure that this observation is not likely to be an artifact of the volatility outliers that are bound to exist in these circumstances. A more intuitive explanation is that the importance of CSP (and the set of control variables) as a determinant of market risk increases in times of economic turbulence.

It could be argued that because both market crises happened in the latter half our entire sample (2000 to 2002 for the dot-com bubble and 2008-2009 for the credit crisis), the results coming from the sample splits into high and low volatility periods might in fact reflect 
a changing external environment with respect to societal expectations of firms. In order to examine this assertion we choose to split our sample in the middle of each time series dimension and create two subsamples: one from 1992 to 2000 and one from 2001 to 2009 (the dates refer to the financial data, the CSP variables being lagged by a year). We then repeat our original analysis and compare the earlier period results with the ones coming from the low volatility sample and the later period results with those of the high volatility sample. Despite the fact that these pairs of samples have many firm-year observations in common they do not really lead to similar conclusions. The coefficient estimates coming from the 1990s and 2000s subsamples are generally insignificant, small in size, and often take different signs from the ones estimated when the entire dataset is split according to the levels of overall volatility. So it appears that the inferences that are drawn based on the splitting of our panel into high and low volatility periods are not influenced by a changing external environment in regards to CSP.

The general issue of endogeneity becomes more topical when discussing the results of the analyses of the volatility subsamples. It has been stated that in order to account for the potential existence of a contemporaneous, bidirectional association between CSP and firm risk, we lagged the independent variables that are used in our models. However, in an attempt to address the possibility that there is a two--way lead-lag effect between the two variables of concern, we estimate alternative models in which systematic risk is the lagged independent variable and the various individual components of social strengths and concerns are the regressands. We do so for our entire panel dataset as well as for the high volatility and low volatility periods subsamples. The results of this robustness test strongly indicate that there is no economically significant evidence of a relationship running between systematic risk and subsequent CSP. The algebraic values of the estimated slope coefficients are particularly low 
and their statistical significance lower (or at most comparable in size) with that of the results of the main analysis. The same applies when aggregate strengths and aggregate concerns are used as dependent variables.

\section{Conclusions}

This study investigates the relationship between corporate social performance and financial risk for an extensive panel data sample of US companies between the years 1992 and 2009. In addition, the association between CSP and investor utility is examined. The main finding is that most of the individual social strength components (Community, Diversity, Employment, Product safety and quality) are negatively but insignificantly associated with systematic firm risk while most of the individual social concern components (Community, Employment, Environment) are significantly positively related to measures of systematic risk. The fact that the use of both conventional and downside risk measures leads to the same conclusions adds convergent validity to the analysis. Utility measures lead to results of great variability and small statistical significance in accordance with the fact that there is no clear consensus in the literature that researches the "wealth-enhancing" effects of CSP. Even with the additional inclusion of higher moments (skewness and kurtosis), it appears that the risk/return trade-off is such that no clear utility gain or loss can be realized by investing in firms characterized by different levels of social and environmental performance.

The results of aggregate strength and concern measures are aligned with those of the individual components and their impacts on risk are actually more pronounced. Interesting conclusions are also drawn when we try to investigate how generalized conditions of market volatility moderate the CSP-risk relation. In comparison with the results of the main part of this study, it becomes more visible that, in times of small or moderate levels of volatility, 
firms that engage in socially responsible behavior are characterized by lower levels of market risk, while during times of high volatility, firms that are socially irresponsible are associated with higher levels of financial risk.

By concentrating on an under-researched question, this study manages to uncover new pieces of the CSP-CFP puzzle. The finding that corporate social performance affects the ability of a company to cope with adverse systemic economic shocks should be considered by firm managers when they make strategic business decisions and private or institutional investors when they are trying to identify the optimal asset allocation of their wealth. The latter is especially true for those institutional investors (pension funds, life assurance companies) that have significantly predictable outflows to beneficiaries and want to invest in shares that are not very volatile. Future research may use this study as a starting point to examine the mediating and moderating effects of other factors in the CSP-risk relation, such as the interactions between social/environmental strengths and concerns and their potential impact on financial risk and returns, or concentrate on revealing the nature of the idiosyncratic elements of risk that are affected by socially/environmentally responsible and irresponsible behavior. 


\section{References}

Abel, A.B., 1990, "Asset Prices Under Habit Formation and Catching up with the Joneses," American Economic Review 80, 38-42.

Aupperle, K.E., A.B. Carroll, and J.D. Hatfield, 1985, "An Empirical Examination of the Relationship between Corporate Social Responsibility and Profitability," Academy of Management Journal 28, 446-463.

Aupperle, K.E. and D. Van Pham, 1989, "An Expanded Investigation into the Relationship of Corporate Social Responsibility and Financial Performance," Employee Responsibilities and Rights Journal 2, 263-274.

Baldwin, S.A., J.W. Tower, L. Litvak, J.F. Karpen, H.F. Jackson, and B. McTigue, 1986, "Pension Funds and Ethical Investment," Council on Economic Priorities, New York, NY.

Baltagi, B.H. and Y-J. Chang, 1994, "Incomplete Panels: A Comparative Study of Alternative Estimators for the Unbalanced Ene-way Error Component Regression Model," Journal of Econometrics 62, 67-89.

Baltagi, B.H., 2005. Econometric Analysis of Panel Data, New York, NY, John Wiley and Sons.

Bauer, R., K. Koedijk, and R. Otten, 2005, "International Evidence on Ethical Mutual Fund Performance and Investment Style," Journal of Banking and Finance 29, 1751-1767.

Bawa, V.S. and E.B. Lindenberg, 1977, "Capital Market Equilibrium in a Mean-lower Partial Moment Framework," Journal of Financial Economics 5, 189-200.

Beaver, W, P. Kettler, and M. Scholes, 1970, "The Association between Market Determined and Accounting Determined Risk Measures," Accounting Review 45, 654-682.

Benson, B.W., W.N. Davidson III, H. Wang, and D. Worrell, 2011, "Deviations from Expected Stakeholder Management, Firm Value, and Corporate Governance," Financial Management 40, 39-81.

Blume, M.E., 1980, "Stock Returns and Dividend Yields: Some more Evidence," Review of Economics and Statistics 567-577.

Brammer, S., C. Brooks, and S. Pavelin, 2006, "Corporate Social Performance and Stock Returns: UK Evidence from Disaggregate Measures," Financial Management 35, 97-116.

Cameron, A.C. and P.K. Trivedi, 2005. Microeconometrics: Methods and Applications, New York, NY, Cambridge University Press. 
Campbell, J.Y. and J.H. Cochrane, 1999, "By Force of Habit: A Consumption-based Explanation of Aggregate Stock Market Behavior," Journal of Political Economy 107, 205251.

Chan, K.C. and N. Chen, 1991, "Structural and Return Characteristics of Small and Large firms," Journal of Finance 46, 1467-1484.

Chen C., W. Guo, and N. Tay, 2010, "Are Member Firms of Corporate Groups less Risky?" Financial Management 39, 59-82.

Constantinides, G.M., 1990, "Habit Formation: A Resolution of the Equity Premium Puzzle," Journal of Political Economy 519-543.

Cox, P., S. Brammer, and A. Millington, 2004, "An Empirical Examination of Institutional Investor Preferences for Corporate Social Performance," Journal of Business Ethics 52, 27 43.

DeFusco, R.A., G.V. Karels, and K. Muralidhar, 1996, "Skewness Persistence in US common Stock Returns: Results from Bootstrapping Tests," Journal of Business Finance and Accounting 23, 1183-1196.

Diamond, D.W., 1991, "Monitoring and Reputation: The Choice between Bank Loans and Directly Placed Debt," Journal of Political Economy 99, 689-721.

Donaldson, T. and L.E. Preston, 1995, "The Stakeholder Theory of the Corporation: Concepts, Evidence, and Implications," Academy of Management Review 20, 65-91.

Drehmann, M. and K. Nikolaou, 2009, "Funding Liquidity Risk: Definition and Measurement," Working Paper Series 1024, European Central Bank.

Edmans, A., 2011, "Does the Stock Market fully Value Intangibles? Employee Satisfaction and Equity Prices," Journal of Financial Economics, forthcoming.

Eichengreen, B. and H.K. O'Rourke, 2009, "A Tale of Two Depressions," Vox: ResearchBased Policy Analysis and Commentary from Leading Economists, available online at http://www.voxeu.org/index.php?q=node/3421.

Fama, E.F. and K.R. French, 1992, "The Cross-section of Expected Stock Returns," Journal of Finance 47, 427-465.

Friedman, M., 1970, "The Social Responsibility of Business is to Increase its Profits," New York Times Magazine 32, 122-126.

Godfrey, P.C., 2005, "The Relationship between Corporate Philanthropy and Shareholder Walth: A Risk Management Perspective," Academy of Management Review 30, 777. 
Godfrey, P.C., C.B. Merrill, and J.M. Hansen, 2009, "The Relationship between Corporate Social Responsibility and Shareholder Value: An Empirical Test of the Risk Management Hypothesis," Strategic Management Journal 30, 425-445.

Griffin, J.J. and J.F. Mahon, 1997, "The Corporate Social Performance and Corporate Financial Performance Debate," Business and Society 36, 5-31.

Harlow, W.V. and R.K.S. Rao, 1989, "Asset Pricing in a Generalized Mean-lower Partial Moment Framework: Theory and Evidence," Journal of Financial and Quantitative Analysis 24, 285-311.

Harris, L., 2003. Trading and exchanges, New York, NY, Oxford University Press.

Hillman, A.J. and G.D. Keim, 2001, "Shareholder Value, Stakeholder Management, and Social Issues: What's the Bottom Line?" Strategic Management Journal 22, 125-139.

Jones, T.M., 1995, "Instrumental Stakeholder Theory: A Synthesis of Ethics and Economics," Academy of Management Review 20, 404-437.

Lankoski, L., 2009, "Differential Economic Impacts of Corporate Responsibility Issues," Business \& Society 48, 206-224.

Luo, X. and C.B. Bhattacharya, 2009, "The Debate over Doing Good: Corporate Social Performance, Strategic Marketing Levers, and Firm-idiosyncratic Rsk," Journal of Marketing 73, 198-213.

Margolis, J.D. and J.P. Walsh, 2003, "Misery Loves Companies: Rethinking Social Initiatives by Business," Administrative Science Quarterly 48, 268-305.

Markowitz, H., 1991. Portfolio selection: Efficient Diversification of Investments, New York, NY, John Wiley \& Sons.

Mattingly, J.E. and S.L. Berman, 2006, "Measurement of Corporate Social Action: Discovering Taxonomy in the Kinder Lydenburg Domini Ratings Data," Business \& Society $45,20-46$.

McGuire, J.B., A. Sundgren, and T. Schneeweis, 1988, "Corporate Social Responsibility and Firm Financial Performance," Academy of Management Journal 31, 854-872.

McGuire, J.B., S. Dow, and K. Argheyd, 2003, "CEO Incentives and Corporate Social Performance," Journal of Business Ethics 45, 341-359.

McWilliams, A. and D. Siegel, 2000, "Corporate Social Responsibility and Financial Performance: Correlation or Misspecification?" Strategic Management Journal 21, 603-609.

Meijer, M.M. and T. Schuyt, 2005, "Corporate Social Performance as a Bottom Line for Consumers," Business \& Society 44, 442-461. 
Modigliani, F. and M.H. Miller, 1958, "The Cost of Capital, Corporation Finance and the Theory of Investment," American Economic Review 48, 261-297.

Orlitzky, M. and J.D. Benjamin, 2001, "Corporate Social Performance and Firm Risk: A Meta-analytic Review," Business \& Society 40, 369-396.

Petersen, M.A., 2009, "Estimating Standard Errors in Finance Panel Data Sets: Comparing Approaches," Review of Financial Studies 22, 435-480.

Renneboog, L., J. Ter Horst, and C. Zhang, 2008a, "The Price of Ethics and Stakeholder Governance: The Performance of Socially Responsible Mutual Funds," Journal of Corporate Finance 14, 302-322.

Renneboog, L., J. Ter Horst, and C. Zhang, 2008b, "Socially Responsible Investments: Institutional Aspects, Performance, and Investor Behavior," Journal of Banking and Finance 32, 1723-1742.

Ryan, L.V. and M. Schneider, 2002, "The Antecedents of Institutional Investor Activism," Academy of Management Review 27, 554-573.

Salama, A., K.P. Anderson, and S. Toms, 2009, "Does Community and Environmental Responsibility Affect Firm Risk? Evidence from UK Panel Data 1994-2006," Business Ethics: A European Review 20, 192-204.

Sharfman, M.P. and C.S. Fernando, 2008, "Environmental Risk Management and the Cost of Capital," Strategic Management Journal 29, 569-592.

Spicer, B.H., 1978, "Investors, Corporate Social Performance and Information Disclosure: An Empirical Study," Accounting Review, 53, 94-111.

Turnbull, P.W. and M.L. Gibbs, 1987, "Marketing Bank Services to Corporate Customers: The Importance of Relationships," International Journal of Bank Marketing 5, 19-26.

Tversky, A. and D. Kahneman, 1991, "Loss Aversion in Riskless Choice: A ReferencedependentModel," Quarterly Journal of Economics 106, 1039-1061.

Ullmann, A.A., 1985, "Data in Search of a Theory: A Critical Examination of the Relationships Among Social Performance, Social Disclosure, and Economic Performance of US Firms," Academy of Management Review 10, 540-557.

Waddock, S.A., 2003, "Myths and Realities of Social Investing," Organization and Environment 16, 369-380.

Waddock, S.A. and S.B. Graves, 1997, "The Corporate Social Performance-financial Performance Link," Strategic Management Journal 18, 303-319. 
Wood, D.J. and R.E. Jones, 1995, "Stakeholder Mismatching: A Theoretical Problem in Empirical Research on Corporate Social Performance," International Journal of Organizational Analysis 3, 229-267. 


\section{Figure 1. Omnipresent Indicators of Qualitative Issue Areas of Interest}
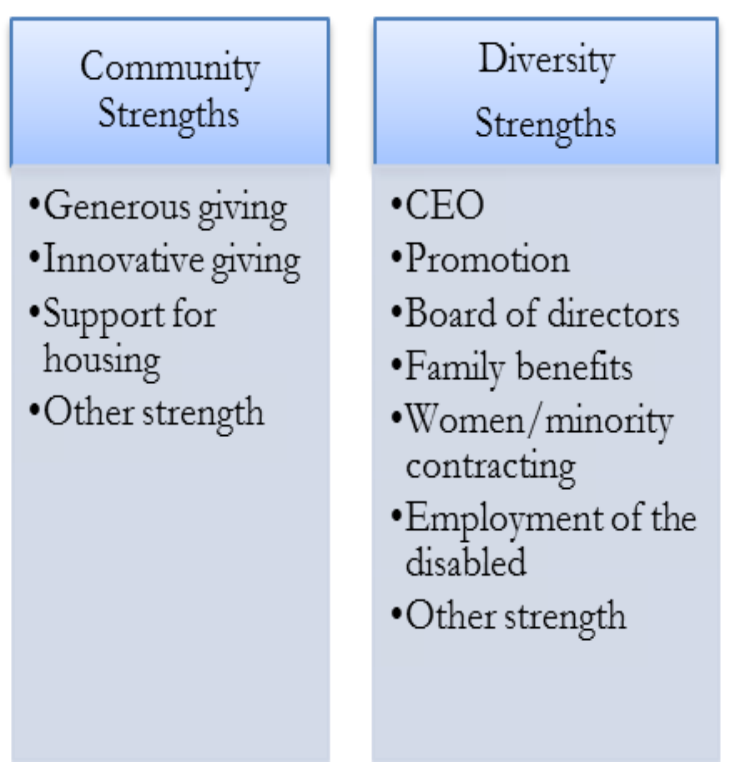

\begin{tabular}{|l|}
\hline $\begin{array}{c}\text { Environment } \\
\text { Strengths }\end{array}$ \\
- Beneficial \\
products and \\
services \\
- Pollution \\
prevention \\
-Recycling \\
-Alternative fuels \\
-Other strength
\end{tabular}
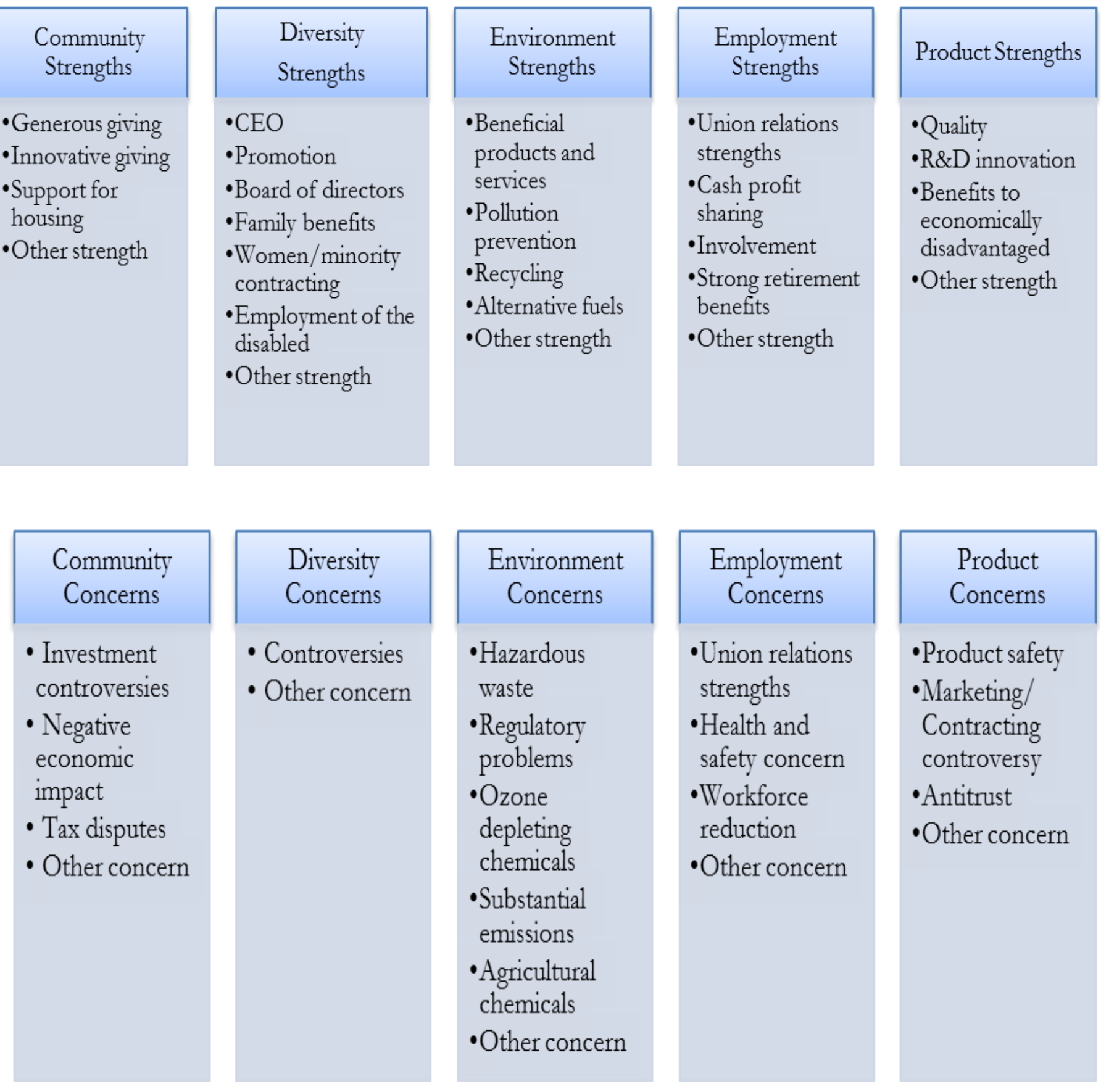

\section{Environment Concerns}

-Hazardous

waste

- Regulatory problems

- Ozone depleting chemicals

-Substantial emissions

-Agricultural chemicals

- Other concern

\section{Employment Concerns}

-Union relations strengths

-Health and safety concern -Workforce reduction - Other concern

\section{Product Concerns}

-Product safety

- Marketing/

Contracting controversy

- Antitrust

- Other concern 
Figure 2. Annualised Weekly Standard Deviation of Returns for Year by Year S\&P 500 Samples, 1992-2009

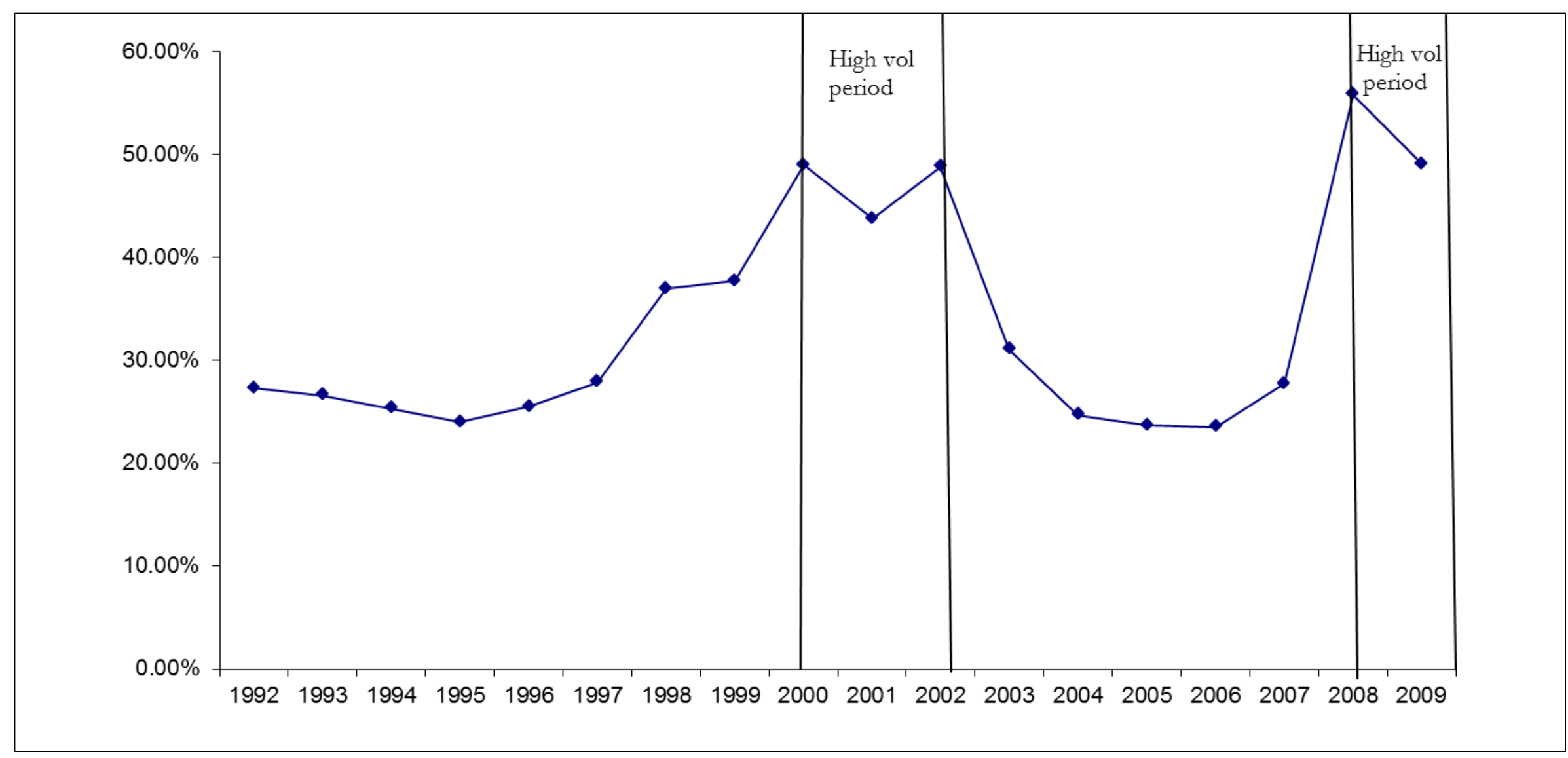




\section{Table I. Descriptive Statistics of Key Variables}

Table contains mean, median, maximum and minimum values and standard deviations for all variables of interest. $\log (\mathrm{mv})$ is the logarithm of market capitalization, mtbv is market-to-book value, dy is dividend yield, tdce is the total debt to common equity ratio; HR Beta and BL Beta refer to the HarlowRao and Bawa and Lindenberg betas; CE refers to certainty equivalents with absolute risk aversion $(\gamma)$ in parenthesis.

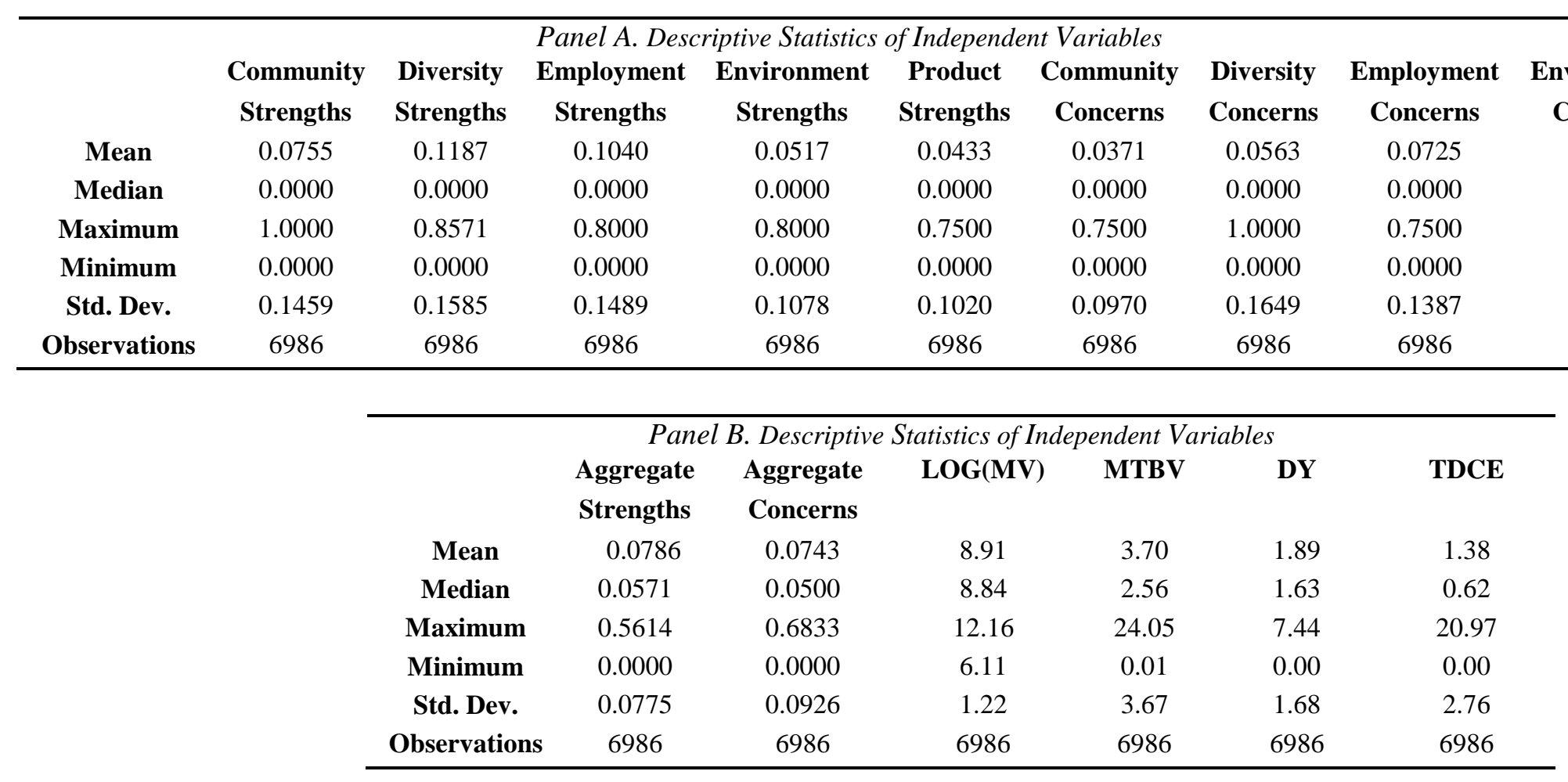




\begin{tabular}{ccccccc}
\hline & \multicolumn{7}{c}{ Panel C. Descriptive Statistics of Dependent Variables } \\
Mean & 1.016 & 1.024 & 1.031 & -0.001 & -0.006 & \multirow{2}{*}{$(\boldsymbol{\gamma} \mathbf{\gamma}) \mathbf{5})$} \\
Median & 0.955 & 0.967 & 0.955 & 0.000 & -0.002 & -0.046 \\
Maximum & 2.967 & 2.876 & 3.181 & 0.013 & 0.009 & 0.002 \\
Minimum & -0.139 & -0.187 & -0.312 & -0.038 & -0.078 & -0.899 \\
Std. Dev. & 0.565 & 0.576 & 0.641 & 0.008 & 0.013 & 0.116 \\
Skewness & 0.804 & 0.683 & 0.752 & -1.786 & -2.882 & -5.611 \\
Sum & 7094.29 & 7150.18 & 7204.33 & -10.22 & -41.64 & -320.07 \\
Observations & 6986 & 6986 & 6986 & 6986 & 6986 & 6986 \\
\hline
\end{tabular}


Table II. Correlation Coefficients Between Key Variables and CSP Values by Industry

COMS and COMC are community strengths(s) and community concerns(c), respectively, DIV is used for the diversity indicator, ENV for the environment indicator, EMP for the employment indicator, PSQ for the product safety and quality indicator; HR Beta and BL Beta refer to the Harlow-Rao and Bawa and Lindenberg betas; CE refers to certainty equivalents with absolute risk aversion $(\gamma)$. COMS and COMC are community strengths(s) and community concerns(c), respectively, DIV is used for the diversity indicator, ENV for the environment indicator, EMP for the employment indicator, PSQ for the product safety and quality indicator.

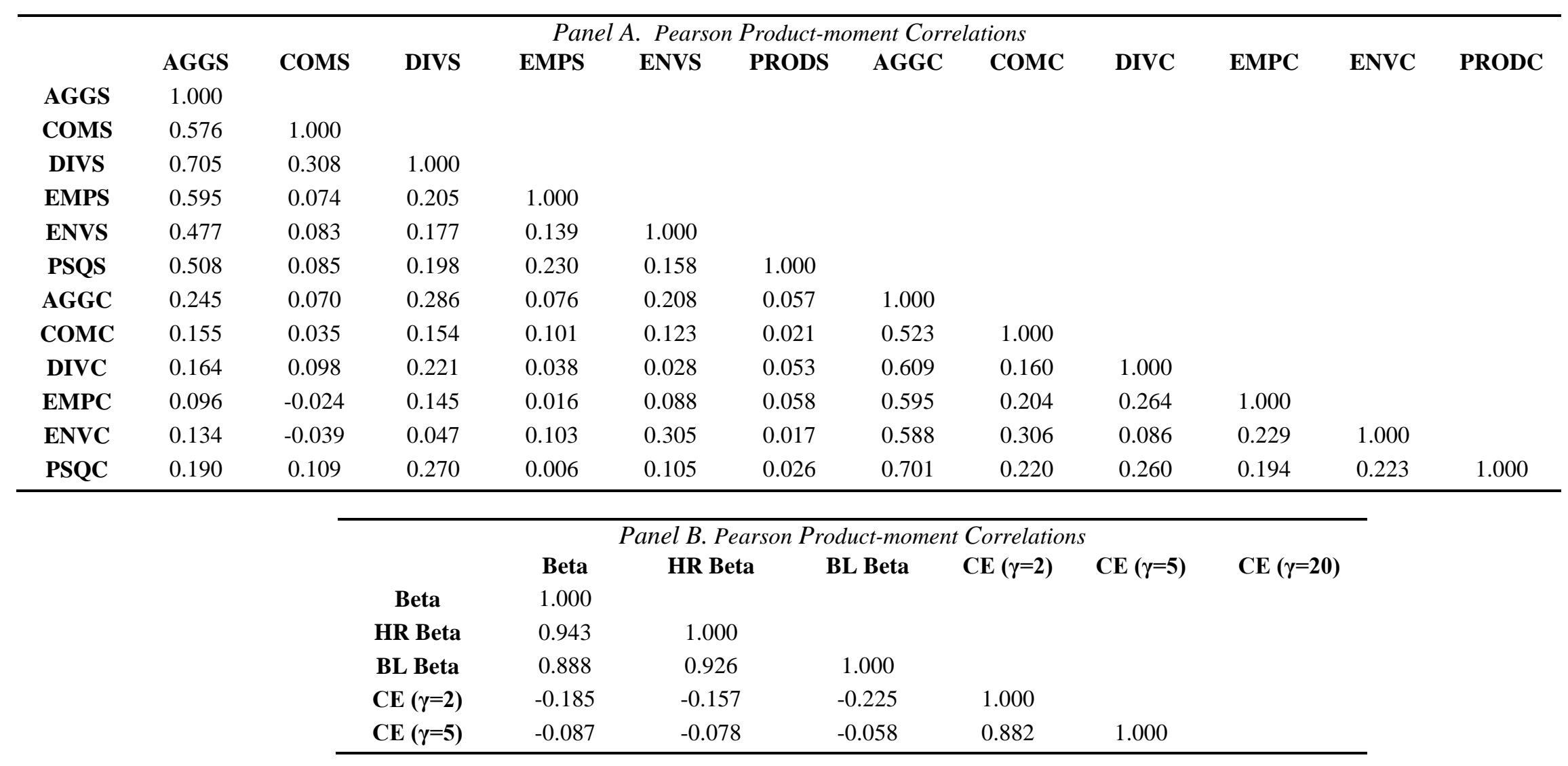




\begin{tabular}{lllllll}
\hline $\mathbf{C E}(\boldsymbol{\gamma}=\mathbf{2 0})$ & -0.071 & -0.063 & -0.037 & 0.858 & 0.999 & 1.000 \\
\hline
\end{tabular}

\begin{tabular}{|c|c|c|c|c|c|c|c|c|c|c|}
\hline \multicolumn{11}{|c|}{ Panel C. Mean Values of KLD Scores by Industry } \\
\hline & Automobiles & Banks & $\begin{array}{c}\text { Basic } \\
\text { Resources }\end{array}$ & Chemicals & $\begin{array}{c}\text { Construction } \\
\text { Materials }\end{array}$ & Finance & $\begin{array}{c}\text { Food \& } \\
\text { Beverage }\end{array}$ & Healthcare & $\begin{array}{l}\text { Industrial } \\
\text { Goods }\end{array}$ & Insurance \\
\hline COMS & 0.0426 & 0.2107 & 0.0581 & 0.0613 & 0.0315 & 0.1813 & 0.1057 & 0.0768 & 0.0368 & 0.0945 \\
\hline DIVS & 0.1534 & 0.1673 & 0.0316 & 0.0756 & 0.0204 & 0.1758 & 0.1742 & 0.1447 & 0.0690 & 0.1098 \\
\hline EMPS & 0.1911 & 0.1113 & 0.0157 & 0.0879 & 0.0857 & 0.0974 & 0.0859 & 0.0967 & 0.0898 & 0.0847 \\
\hline ENVS & 0.1052 & 0.0066 & 0.1107 & 0.1144 & 0.0588 & 0.0029 & 0.0446 & 0.0507 & 0.0650 & 0.0046 \\
\hline PSQS & 0.0500 & 0.0282 & 0.0258 & 0.0632 & 0.0063 & 0.0742 & 0.0148 & 0.0564 & 0.0637 & 0.0106 \\
\hline COMC & 0.0500 & 0.0813 & 0.0526 & 0.0302 & 0.0231 & 0.0385 & 0.0336 & 0.0163 & 0.0409 & 0.0122 \\
\hline DIVC & 0.1407 & 0.0579 & 0.0332 & 0.0253 & 0.0252 & 0.0989 & 0.0607 & 0.0359 & 0.0635 & 0.1026 \\
\hline EMPC & 0.1296 & 0.0310 & 0.1301 & 0.0788 & 0.0819 & 0.0266 & 0.0852 & 0.0290 & 0.0897 & 0.0285 \\
\hline ENVC & 0.1988 & 0.0000 & 0.2724 & 0.2685 & 0.1653 & 0.0006 & 0.0951 & 0.0621 & 0.1119 & 0.0049 \\
\hline PSQC & 0.1630 & 0.1226 & 0.0470 & 0.1265 & 0.1597 & 0.2115 & 0.1336 & 0.2823 & 0.1082 & 0.1604 \\
\hline Observations & 185 & 363 & 271 & 257 & 119 & 273 & 305 & 612 & 1040 & 307 \\
\hline
\end{tabular}

\begin{tabular}{|c|c|c|c|c|c|c|c|c|c|}
\hline \multicolumn{10}{|c|}{ Panel C. Mean Values of KLD Scores by Industry (Continued) } \\
\hline & Media & $\begin{array}{c}\text { Oil \& } \\
\text { Gas }\end{array}$ & $\begin{array}{c}\text { Personal \& } \\
\text { Household } \\
\text { Goods }\end{array}$ & $\begin{array}{c}\text { Real } \\
\text { Estate }\end{array}$ & Retail & Technology & Telecoms & $\begin{array}{c}\text { Travel \& } \\
\text { Leisure }\end{array}$ & Utilities \\
\hline COMS & 0.0661 & 0.0303 & 0.1173 & 0.0069 & 0.0742 & 0.0366 & 0.1205 & 0.0303 & 0.0756 \\
\hline DIVS & 0.1518 & 0.0402 & 0.1393 & 0.0298 & 0.1188 & 0.1581 & 0.2282 & 0.1817 & 0.0996 \\
\hline EMPS & 0.0233 & 0.1403 & 0.0889 & 0.0167 & 0.0739 & 0.1842 & 0.0993 & 0.1225 & 0.0494 \\
\hline ENVS & 0.0314 & 0.0806 & 0.0457 & 0.0028 & 0.0182 & 0.0478 & 0.0029 & 0.0382 & 0.1155 \\
\hline
\end{tabular}




\begin{tabular}{cccccccccc}
\hline PSQS & 0.0886 & 0.0148 & 0.0290 & 0.0000 & 0.0337 & 0.0684 & 0.0360 & 0.0361 & 0.0104 \\
COMC & 0.0123 & 0.1310 & 0.0290 & 0.0000 & 0.0160 & 0.0180 & 0.0468 & 0.0116 & 0.0652 \\
DIVC & 0.0291 & 0.0507 & 0.0264 & 0.0208 & 0.1290 & 0.0132 & 0.1511 & 0.1214 & 0.0312 \\
EMPC & 0.0852 & 0.1289 & 0.0492 & 0.0347 & 0.1079 & 0.0645 & 0.1025 & 0.0809 & 0.0687 \\
ENVC & 0.0082 & 0.2089 & 0.0401 & 0.0231 & 0.0098 & 0.0166 & 0.0228 & 0.0154 & 0.1674 \\
PSQC & 0.0628 & 0.0944 & 0.1011 & 0.0486 & 0.1155 & 0.0522 & 0.2194 & 0.0780 & 0.1403 \\
Observations & 223 & 355 & 569 & 72 & 593 & 833 & 139 & 173 \\
\hline
\end{tabular}


Table III. Fixed Effects Regressions of the Individual Components Model

Cell entries are parameter estimates; each column corresponds to the output of a different fixed effects regression; all dependent variables have been winsorized at the $1 \%$ level; $\alpha$ is the average of the firm-specific fixed effects; $\beta$ coms and $\beta$ comc are the slope coefficients for the community strengths(s) and community concerns(c) indicators, respectively, div is used for the diversity indicator, env for the environment indicator, emp for the employment indicator, psq for the product indicator, $\log (\mathrm{mv})$ is the logarithm of market capitalization, mtbv is market-to-book value, dy is dividend yield, tdce is the total debt to common equity ratio; HR Beta and BL Beta refer to the Harlow-Rao and Bawa and Lindenberg betas; CE refers to certainty equivalents with absolute risk aversion ( $\gamma$ ) in parenthesis; entries of the last row are adjusted $R^{2}$ values for each regression. $t$-statistics in parentheses.

\begin{tabular}{|c|c|c|c|c|c|c|}
\hline & Beta & HR Beta & BL Beta & CE $(\gamma=2)$ & $\mathrm{CE}(\gamma=5)$ & CE $(\gamma=20)$ \\
\hline \multirow[t]{2}{*}{$\alpha$} & $1.1901 * * *$ & $1.4963 * * *$ & $0.8264 * * *$ & $0.0429 * * *$ & $0.0537 * * *$ & $0.2270^{* * *}$ \\
\hline & (10.7609) & (12.9393) & $(6.2061)$ & $(24.0130)$ & (19.0429) & $(8.8585)$ \\
\hline \multirow[t]{2}{*}{$\beta_{\text {coms }}$} & -0.0429 & -0.0569 & -0.0014 & -0.0001 & 0.0012 & 0.0168 \\
\hline & $(-0.6916)$ & $(-0.8777)$ & $(-0.0190)$ & $(-0.0850)$ & $(0.7654)$ & (1.1727) \\
\hline \multirow{2}{*}{$\boldsymbol{\beta}_{\text {divs }}$} & -0.0873 & -0.0538 & -0.0714 & 0.0011 & 0.0001 & -0.0181 \\
\hline & $(-1.3359)$ & $(-0.7872)$ & $(-0.9071)$ & (1.0405) & $(0.0589)$ & $(-1.1928)$ \\
\hline \multirow[t]{2}{*}{$\boldsymbol{\beta}_{\text {emps }}$} & -0.0860 & -0.0837 & -0.0892 & -0.0008 & $-0.0035 * *$ & $-0.0485 * * *$ \\
\hline & $(-1.4044)$ & $(-1.3080)$ & $(-1.2097)$ & $(-0.8234)$ & $(-2.2584)$ & $(-3.4214)$ \\
\hline \multirow[t]{2}{*}{$\beta_{\text {envs }}$} & 0.0272 & 0.0342 & 0.1095 & -0.0014 & -0.0013 & 0.0084 \\
\hline & $(0.3482)$ & (0.4194) & (1.1653) & $(-1.0733)$ & $(-0.6536)$ & $(0.4648)$ \\
\hline \multirow[t]{2}{*}{$\boldsymbol{\beta}_{\mathrm{psqs}}$} & -0.1452 & -0.1164 & -0.0931 & 0.0001 & 0.0003 & 0.0187 \\
\hline & $(-1.4742)$ & $(-1.1295)$ & $(-0.7851)$ & $(0.0495)$ & $(0.1246)$ & $(0.8184)$ \\
\hline \multirow[t]{2}{*}{$\beta_{\text {come }}$} & $0.1622 * *$ & $0.1755 * *$ & 0.1327 & -0.0003 & -0.0011 & 0.0023 \\
\hline & (2.0722) & (2.1448) & $(1.4076)$ & $(-0.2088)$ & $(-0.5465)$ & $(0.1259)$ \\
\hline \multirow[t]{2}{*}{$\beta_{\text {divc }}$} & 0.0342 & 0.0303 & 0.0104 & 0.0001 & 0.0004 & 0.0045 \\
\hline & (0.7397) & (0.6264) & $(0.1872)$ & $(0.0853)$ & $(0.3266)$ & $(0.4163)$ \\
\hline \multirow[t]{2}{*}{$\beta_{\text {empc }}$} & $0.1906^{* * *}$ & $0.1271 * *$ & $0.1307^{*}$ & -0.0010 & $-0.0035^{* *}$ & $-0.0312 * *$ \\
\hline & (3.415) & (2.1781) & (1.9447) & $(-1.1319)$ & $(-2.4826)$ & $(-2.4150)$ \\
\hline$\beta_{\text {envc }}$ & $0.1680^{* *}$ & $0.2416^{* * * *}$ & 0.1046 & $0.0037 * * *$ & $0.0055^{* * *}$ & $0.0366^{*}$ \\
\hline
\end{tabular}




\begin{tabular}{|c|c|c|c|c|c|c|}
\hline & $(2.036)$ & $(2.8007)$ & $(1.0534)$ & $(2.7883)$ & $(2.6029)$ & $(1.9142)$ \\
\hline \multirow[t]{2}{*}{$\beta_{\mathrm{psqc}}$} & -0.0456 & -0.0181 & -0.0848 & 0.0005 & 0.0000 & -0.0156 \\
\hline & $(-0.9652)$ & $(-0.3675)$ & $(-1.4919)$ & $(0.5923)$ & $(0.0054)$ & $(-1.4303)$ \\
\hline \multirow[t]{2}{*}{$\beta_{\log (\mathbf{m v})}$} & $-0.0275^{*} *$ & $-0.0623 * * *$ & 0.0146 & $-0.0048 * * *$ & $-0.0061 * * *$ & $-0.0247 * * *$ \\
\hline & $(-2.2117)$ & $(-4.7953)$ & $(0.9728)$ & $(-23.8808)$ & $(-19.2004)$ & $(-8.5736)$ \\
\hline \multirow[t]{2}{*}{$\beta_{\mathrm{mtbv}}$} & 3.6967 & 3.9516 & $7.3366 * *$ & $-0.3689 * * *$ & $-0.6776 * * *$ & $-2.3554 * * *$ \\
\hline & $(1.2928)$ & $(1.3216)$ & (2.131) & $(-7.9944)$ & $(-9.2982)$ & $(-3.5554)$ \\
\hline \multirow[t]{2}{*}{$\beta_{\text {dy }}$} & $0.0176^{* *}$ & $0.0196 * * *$ & $0.0224 * * *$ & $-0.0004 * * *$ & $-0.0015^{* * *}$ & $-0.0182 * * *$ \\
\hline & $(2.526)$ & (2.6879) & $(2.6732)$ & $(-3.1156)$ & $(-8.4567)$ & $(-11.2653)$ \\
\hline \multirow[t]{2}{*}{$\boldsymbol{\beta}_{\text {tdce }}$} & $0.0154 * * *$ & $0.0135 * * *$ & 0.0068 & 0.0001 & 0.0000 & $-0.0031 * * *$ \\
\hline & $(3.2949)$ & $(2.7474)$ & (1.2093) & $(0.9871)$ & $(0.0459)$ & $(-2.8625)$ \\
\hline $\operatorname{Adj} . R^{2}$ & 0.3504 & 0.3162 & 0.2684 & 0.2179 & 0.2577 & 0.1750 \\
\hline
\end{tabular}

***Significant at the 0.01 level

**Significant at the 0.05 level.

*Significant at the 0.10 level. 


\section{Table IV. Fixed Effects Regressions of the Aggregated Components Model}

Cell entries are parameter estimates; each column corresponds to the output of a different fixed effects regression; all dependent variables have been winsorized at the $1 \%$ level; $\alpha$ is the average of the firm specific fixed effects; $\beta_{\text {aggs }}$ and $\beta_{\text {aggc }}$ are the slope coefficients for the aggregate strengths(s) and aggregate concerns(c) indicators, respectively, $\log (\mathrm{mv})$ is the logarithm of market capitalization, mtbv is market-to-book value, dy is dividend yield, and tdce is the total debt to common equity ratio; entries of last row are adjusted $R^{2}$ values for each regression.. $t$-statistics in parentheses.

\begin{tabular}{|c|c|c|c|c|c|c|}
\hline & Beta & HR Beta & BL Beta & $\mathrm{CE}(\gamma=2)$ & $\mathrm{CE}(\gamma=5)$ & $\mathrm{CE}(\gamma=20)$ \\
\hline \multirow[t]{2}{*}{$\alpha$} & $1.1981 * * *$ & $1.4931 * * *$ & $0.8426 * * *$ & $0.0427 * * *$ & $0.0542 * * *$ & $0.2395 * * *$ \\
\hline & (11.0700) & (13.1966) & $(6.4681)$ & (24.4356) & (19.6473) & (9.5460) \\
\hline \multirow{2}{*}{$\boldsymbol{\beta}_{\text {aggs }}$} & $-0.2938 * *$ & -0.2402 & -0.1319 & -0.0008 & -0.0038 & -0.0439 \\
\hline & $(-2.0145)$ & $(-1.5757)$ & $(-0.7518)$ & $(-0.3588)$ & $(-1.0263)$ & $(-1.2993)$ \\
\hline \multirow{2}{*}{$\boldsymbol{\beta}_{\text {agge }}$} & $0.3629 * * *$ & $0.3760 * * *$ & 0.1589 & 0.0013 & -0.0018 & -0.0392 \\
\hline & (3.4165) & (3.3857) & $(1.2426)$ & $(0.7777)$ & $(-0.6581)$ & $(-1.5922)$ \\
\hline \multirow[t]{2}{*}{$\beta_{\log (\mathbf{m v})}$} & $-0.0288 * *$ & $-0.0618 * * *$ & 0.0120 & $-0.0047 * * *$ & $-0.0061 * * *$ & $-0.0260 * * *$ \\
\hline & $(-2.3737)$ & $(-4.8684)$ & $(0.8226)$ & $(-24.2233)$ & $(-19.7399)$ & $(-9.2350)$ \\
\hline \multirow{2}{*}{$\boldsymbol{\beta}_{\mathrm{mtbv}}$} & 3.6470 & 3.7993 & $7.2500^{* *}$ & $-0.3705^{* * *}$ & $-0.6795^{* * *}$ & $-2.3489 * * *$ \\
\hline & (1.2795) & (1.2751) & $(2.1134)$ & $(-8.0595)$ & $(-9.3534)$ & $(-3.5551)$ \\
\hline \multirow{2}{*}{$\boldsymbol{\beta}_{\mathrm{dy}}$} & $0.0188 * * *$ & $0.0206^{* * *}$ & $0.0234 * * *$ & $-0.0004 * * *$ & $-0.0015^{* * *}$ & $-0.0183 * * *$ \\
\hline & (2.7122) & (2.8294) & $(2.8029)$ & $(-3.1331)$ & $(-8.5150)$ & $(-11.3474)$ \\
\hline \multirow[t]{2}{*}{$\boldsymbol{\beta}_{\text {tdce }}$} & $0.0153 * * *$ & $0.0134 * * *$ & 0.0068 & 0.0001 & 0.0000 & $-0.0032 * * *$ \\
\hline & (3.2789) & (2.7542) & $(1.2115)$ & $(0.9570)$ & $(0.0157)$ & $(-2.9292)$ \\
\hline $\operatorname{Adj} . R^{2}$ & 0.3495 & 0.3157 & 0.2680 & 0.2176 & 0.2567 & 0.1731 \\
\hline
\end{tabular}


Table V. The Effects of CSP on Risk During Periods of High Quality Volatility

Cell entries are parameter estimates; $t$-statistics in parentheses; each column corresponds to the output of a different fixed effects regression using data from the periods 2000 to 2002 and 2008 to 2009; all dependent variables have been winsorized at the $1 \%$ level; $\alpha$ is the average of the firm specific fixed effects; $\beta$ coms and $\beta$ comc are the slope coefficients for the community strengths(s) and community concerns(c) indicators respectively, div is used for the diversity indicator, env for the environment indicator, emp for the employment indicator, psq for the product indicator, $\log (\mathrm{mv})$ is the logarithm of market capitalisation, mtbv is market-to-book value, dy is dividend yield, tdce is the total debt to common equity ratio; HR Beta and BL Beta refer to the Harlow-Row and Bawa and Lindenberg betas; entries of last row are adjusted $R^{2}$ values for each regression.

\begin{tabular}{cccc}
\hline $\boldsymbol{\alpha}$ & Beta & HR Beta & BL Beta \\
& -0.2735 & 0.2446 & $-0.6215^{* *}$ \\
$\boldsymbol{\beta}_{\text {coms }}$ & $(-0.9501)$ & $(0.8126)$ & $(-2.0387)$ \\
& -0.1462 & -0.2265 & -0.2393 \\
$\boldsymbol{\beta}_{\text {divs }}$ & $(-0.8146)$ & $(-1.2018)$ & $(-1.2465)$ \\
& $0.3778^{* * *}$ & $0.2845^{*}$ & 0.2485 \\
$\boldsymbol{\beta}_{\text {emps }}$ & $(2.6900)$ & $(1.8594)$ & $(1.5645)$ \\
& 0.0666 & 0.1428 & 0.1244 \\
$\boldsymbol{\beta}_{\text {envs }}$ & $(0.4727)$ & $(0.9560)$ & $(0.7959)$ \\
& -0.0092 & -0.0104 & -0.0205 \\
$\boldsymbol{\beta}_{\text {psqs }}$ & $(-0.0591)$ & $(-0.0612)$ & $(-0.1201)$ \\
& 0.2295 & 0.1050 & 0.0933 \\
$\boldsymbol{\beta}_{\text {comc }}$ & $(1.0938)$ & $(0.4674)$ & $(0.3936)$ \\
& -0.0766 & -0.0506 & -0.0473 \\
$\boldsymbol{\beta}_{\text {divc }}$ & $(-0.4904)$ & $(-0.2960)$ & $(-0.2734)$ \\
& 0.0836 & 0.0709 & 0.0799 \\
& $(0.8396)$ & $(0.6569)$ & $(0.7268)$ \\
\hline
\end{tabular}




\begin{tabular}{cccc}
\hline $\boldsymbol{\beta}_{\text {empc }}$ & $0.3395 * * *$ & $0.2352 * *$ & $0.2488 * *$ \\
& $(3.0710)$ & $(1.9987)$ & $(2.1067)$ \\
$\boldsymbol{\beta}_{\text {envc }}$ & $0.3174 *$ & $0.4966 * * *$ & $0.4767 * *$ \\
& $(1.9409)$ & $(2.7003)$ & 0.1826 \\
$\boldsymbol{\beta}_{\mathbf{p s q c}}$ & 0.1644 & 0.1223 & $(1.5801)$ \\
& $(1.604)$ & $(1.0931)$ & $0.1319 * * *$ \\
$\boldsymbol{\beta}_{\text {log(mv) }}$ & $0.0971 * * *$ & 0.0441 & $(4.0148)$ \\
& $(3.1186)$ & $(1.3606)$ & $18.5876 * * *$ \\
$\boldsymbol{\beta}_{\mathbf{m t b v}}$ & $19.3738 * * *$ & $17.8449 * * *$ & $(3.2838)$ \\
& $(3.7557)$ & $(3.2407)$ & $(6.9493)$ \\
$\boldsymbol{\beta}_{\mathbf{d y}}$ & $0.0967 * * *$ & $0.0929 * * *$ & $0.0201 *$ \\
& $(6.6284)$ & $(6.0011)$ & $(1.7418)$ \\
$\boldsymbol{\beta}_{\text {tdce }}$ & 0.0165 & $0.0195 *$ & 0.4496 \\
\hline Adj. $\boldsymbol{R}^{2}$ & $(1.4878)$ & $(1.6681)$ &
\end{tabular}


Cell entries are parameter estimates; $t$-statistics in parentheses; each column corresponds to the output of a different fixed effects regression using data from the periods 1992 to 1999 and 2003 to 2007; all dependent variables have been winsorized at the 1\% level; $\alpha$ is the average of the firm specific fixed effects; $\beta$ coms and $\beta$ comc are the slope coefficients for the community strengths(s) and community concerns(c) indicators respectively, div is used for the diversity indicator, env for the environment indicator, emp for the employment indicator, psq for the product indicator, $\log (\mathrm{mv})$ is the logarithm of market capitalisation, $\mathrm{mtbv}$ is market-to-book value, dy is dividend yield, tdce is the total debt to common equity ratio; HR Beta and BL Beta refer to the Harlow-Row and Bawa and Lindenberg betas; entries of last row are adjusted $R^{2}$ values for each regression

\begin{tabular}{cccc}
\hline $\boldsymbol{\alpha}$ & Beta & HR Beta & BL Beta \\
& $1.5515^{* * *}$ & $1.8693^{* * * *}$ & $1.0936^{* * *}$ \\
$\boldsymbol{\beta}_{\text {coms }}$ & $(10.8895)$ & $(12.4621)$ & $(6.1438)$ \\
& -0.0258 & -0.0385 & 0.0415 \\
$\boldsymbol{\beta}_{\text {divs }}$ & $(-0.3853)$ & $(-0.5436)$ & $(0.4643)$ \\
& $-0.2336^{* * *}$ & $-0.1777^{* *}$ & $-0.2098^{* *}$ \\
$\boldsymbol{\beta}_{\text {emps }}$ & $(-3.0756)$ & $(-2.2188)$ & $(-2.1373)$ \\
& $-0.1664^{* *}$ & $-0.2017 * *$ & $-0.1758^{*}$ \\
$\boldsymbol{\beta}_{\text {envs }}$ & $(-2.1985)$ & $(-2.5021)$ & $(-1.8429)$ \\
& 0.1065 & 0.1203 & 0.1650 \\
$\boldsymbol{\beta}_{\text {psqs }}$ & $(1.1928)$ & $(1.2912)$ & $(1.4483)$ \\
& $-0.2909^{* *}$ & -0.2041 & -0.1378 \\
\hline
\end{tabular}




\begin{tabular}{|c|c|c|c|}
\hline & $(-2.2748)$ & $(-1.5941)$ & $(-0.8734)$ \\
\hline \multirow[t]{2}{*}{$\boldsymbol{\beta}_{\text {comc }}$} & $0.2305^{* *}$ & $0.2293 * *$ & 0.1442 \\
\hline & $(2.3058)$ & $(2.1221)$ & $(1.1681)$ \\
\hline \multirow[t]{2}{*}{$\boldsymbol{\beta}_{\text {dive }}$} & -0.0055 & -0.0087 & -0.0388 \\
\hline & $(-0.0997)$ & $(-0.1533)$ & $(-0.5787)$ \\
\hline \multirow[t]{2}{*}{$\boldsymbol{\beta}_{\mathrm{empc}}$} & 0.1099 & 0.084 & 0.1345 \\
\hline & (1.437) & $(1.0342)$ & (1.4193) \\
\hline \multirow[t]{2}{*}{$\boldsymbol{\beta}_{\text {envc }}$} & $0.1770 *$ & $0.2215^{* *}$ & 0.0722 \\
\hline & $(1.7407)$ & $(2.0558)$ & $(0.5938)$ \\
\hline \multirow[t]{2}{*}{$\boldsymbol{\beta}_{\mathrm{psqc}}$} & -0.0830 & -0.0286 & $-0.1290 *$ \\
\hline & $(-1.4914)$ & $(-0.4904)$ & $(-1.8487)$ \\
\hline \multirow[t]{2}{*}{$\beta_{\log (\mathbf{m v})}$} & $-0.0496 * * *$ & $-0.0884 * * *$ & 0.0022 \\
\hline & $(-3.073)$ & $(-5.1971)$ & $(0.1081)$ \\
\hline \multirow[t]{2}{*}{$\boldsymbol{\beta}_{\mathrm{mtbv}}$} & -0.7391 & -1.1290 & 6.5707 \\
\hline & $(-0.2087)$ & $(-0.3048)$ & $(1.444)$ \\
\hline \multirow[t]{2}{*}{$\beta_{\mathrm{dy}}$} & $-0.0482 * * *$ & $-0.0383 * * *$ & $-0.0396 * * *$ \\
\hline & $(-4.9058)$ & $(-3.7061)$ & $(-3.2095)$ \\
\hline \multirow[t]{2}{*}{$\boldsymbol{\beta}_{\text {tdce }}$} & $0.0125^{*}$ & $0.0116^{*}$ & 0.0044 \\
\hline & $(1.9415)$ & (1.7824) & $(0.5382)$ \\
\hline $\operatorname{Adj} . R^{2}$ & 0.3163 & 0.2779 & 0.2244 \\
\hline
\end{tabular}

***Significant at the 0.01 level.

**Significant at the 0.05 level.

*Significant at the 0.10 level. 
